\title{
Redox-Responsive Viologen-Mediated Self-Assembly of CB[7]-Modified Patchy Particles
}

Farah Benyettou, Xiaolong Zheng, Elizabeth Elacqua, Yu Wang, Parastoo Dalvand, Zouhair Asfari, John-Carl Olsen, Dong Suk Han, Na'il Saleh, Mourad Elhabiri, Marcus Weck* and Ali Trabolsi*

\section{General Methods}

All reagents were purchased from commercial suppliers (Sigma-Aldrich) and used without further purification. Nanopure water (conductivity of $0.06 \mu \mathrm{S} \mathrm{cm}^{-1}$ ), obtained from a Millipore Gradiant Elix3/A10 system was used to prepare sample solutions. Size and morphology of the patchy particles were determined by scanning electron microscopy (FEI Quanta FEG 450). Dynamic light scattering (DLS) measurements were performed on a Malvern Zetasizer NanoSeries to obtain $\zeta$-potentials of the patchy particles. DLS measurements were made on solutions at $\mathrm{pH}=4$. LifeSpec II spectrometer was used, utilizing TCSPC method to collect the fluorescence lifetimes in the solid state using an EPL-375 picosecond pulsed diode laser $\left(\lambda_{e x}=375 \mathrm{~nm}\right.$, repetition rate $\left.=5 \mathrm{MHz}\right)$ for excitation; and monitored emission maxima at $474 \mathrm{~nm}$. The time-resolved emission (intensity of $\sim 1000-3000$ counts/s) was collected (up to 10,000 counts/s) by a red-sensitive high speed PMT detector (Hamamatsu H5773-04). Optical images were observed on a confocal scanning microscope (Olympus FV1000MPE). Infrared spectra were recorded on an Agilent Technologies Cary 600 Series FTIR Spectrometer using the ATR mode. XPS spectra were recorded on a Kratos Axis Ultra delay-line detector (DLD) X-ray photoelectron spectroscopy (XPS) using monochromatic $\mathrm{Mg} \mathrm{K \alpha}$ radiation (1253.6 eV) from the $\mathrm{Mg}$ anode source.

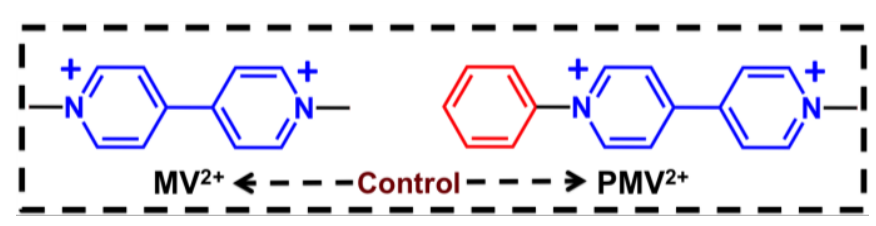

Scheme S1. Chemical structures of methylviologen $\left(\mathrm{MV}^{2+}\right)$ and phenyl-methylviologen $\left(\mathrm{PMV}^{2+}\right)$ used in this study as control. Both viologens were used as a chloride salt. 


\section{1. $\mathrm{DPV}^{2+} / \mathrm{CB}$ [7] Pseudorotaxane}

Starting Materials. The reagents and the starting materials were purchased from commercial source and used without further purification. $\mathbf{P M V}^{2+} \cdot \mathrm{Br} / \mathrm{Cl}$ and $\mathbf{D P V} \mathbf{V}^{2+} \cdot 2 \mathrm{Cl}$ were prepared by some of us. Cucurbit[7]uril (CB[7]) $\left(\mathrm{C}_{42} \mathrm{H}_{42} \mathrm{~N}_{28} \mathrm{O}_{14}\right.$, M. W. $=1162.96 \mathrm{~g} \mathrm{~mol}^{-1}$, Strem chemicals $)$ is a commercial product that was used without further purification.

All solutions were prepared in distilled $\mathrm{H}_{2} \mathrm{O}$ which was further purified by passing it through a mixed bed of ion-exchanger (Bioblock Scientific R3-83002, M3-83006) and activated carbon (Bioblock Scientific ORC-83005). It was then boiled and de-oxygenated using $\mathrm{CO}_{2}$ and $\mathrm{O}_{2}$ free argon prior to use (Sigma Oxiclear cartridge). All stock solutions were prepared using an AG 245 Mettler Toledo analytical balance (precision $0.01 \mathrm{mg}$ ), and complete dissolution in phosphate buffer was achieved using an ultrasonic bath. The experiments were carried out at $25.0(2){ }^{\circ} \mathrm{C}$ maintained with the help of Haake FJ thermostats.

In all the solutions, the $\mathrm{pH}$ was maintained at $7.00 \pm 0.05$ by the use of a $0.1 \mathrm{M}$ phosphate buffer, which was prepared by mixing $30.5 \mathrm{~mL}$ of $\mathrm{Na}_{2} \mathrm{HPO}_{4} \cdot 2 \mathrm{H}_{2} \mathrm{O}(0.2 \mathrm{M})$ (Prolabo) with $19.5 \mathrm{ml}$ of $\mathrm{NaH}_{2} \mathrm{PO}_{4}(0.2 \mathrm{M})$ (Prolabo) and diluting to a total volume of $100 \mathrm{~mL}$. The final $\mathrm{pH}$ of the solution was then set at the required value by using phosphoric acid (85\%, Labosi). The $\mathrm{pH}$ was measured with an $\mathrm{Ag} / \mathrm{AgCl}$ combined glass electrode (Metrohm 6.0234.500, long life) filled with $0.1 \mathrm{M} \mathrm{NaCl}$ (Fluka, p.a.) in $\mathrm{H}_{2} \mathrm{O}$. Standardization of the millivoltmeter and the verification of the linearity of the electrode response were performed using a set of NIST certified commercial Merck buffered solutions ( $\mathrm{pH} 1.68$, $4.00,6.86,7.41$ and 9.18).

Reduction of $\mathbf{P M V} \mathbf{2}^{2}$ and $\mathbf{D P V} \mathbf{2}^{2+}$ into their corresponding radical cationic forms $\left(\mathbf{P M V}^{\bullet+}\right.$ and $\left.\mathbf{D P V}^{\bullet+}\right)$ was achieved under argon $\left(\mathrm{CO}_{2^{-}}\right.$and $\mathrm{O}_{2}$-free argon) with the addition of $\mathrm{Na}_{2} \mathrm{~S}_{2} \mathrm{O}_{4}$ solution in argon purged $\mathrm{H}_{2} \mathrm{O}$. The formation of the radicals was monitored by absorption spectrophotometry using a Cary 5000 UV-Vis.-NIR spectrophotometer.

Spectrophotometric Titrations of Viologen Derivatives by CB[7]. The spectrophotometric titrations of $\mathbf{P M V}^{2+}\left(9.5 \times 10^{-5} \mathrm{M}\right)$ and $\mathbf{D P V}^{12+}\left(5 \times 10^{-5} \mathrm{M}\right)$ with cucurbit[7]uril $(\mathbf{C B}$ [7] $)$ were carried out in Hellma quartz optical cells of $10 \mathrm{~mm}$ pathlength in water at $\mathrm{pH} 7$ (0.1 $\mathrm{M}$ phosphate buffer). Microvolumes of a concentrated solution of $\mathbf{C B}[7]\left(2-5 \times 10^{-3} \mathrm{M}\right)$ were added to the viologen derivatives $\mathbf{P} \mathbf{M V}^{2+}(l=10 \mathrm{~mm}, v=2.5 \mathrm{~mL})$ or $\mathbf{D P V}^{2+}(l=10 \mathrm{~mm}, v=1 \mathrm{~mL})$ with the help of a microburette (Eppendorf). The $[\mathbf{C B}[7]]_{0} /\left[\mathbf{B I P Y}{ }^{2+}\right]_{0}$ ratios were varied from 0 to 3.75 for $\mathbf{P M V}^{2+}$ and from 0 to 5.5 for $\mathbf{D P V}^{2}$, respectively. Special care was taken to ensure that complete equilibration was attained. After each addition, a UV-Vis. spectrum was recorded from 220 to $800 \mathrm{~nm}$ on a Cary 5000 
(Agilent) spectrophotometer maintained at $25.0(2){ }^{\circ} \mathrm{C}$ by the flow of a Dual Cell Pelletier Accessory (Cary Varian).

Stoichiometry of the [n]Pseudorotaxane with $\mathrm{MPV}^{2+}$ and $\mathrm{DPV}^{2+}$ Probed by ESI-MS. Electrospray ionization mass spectra (ESI-MS) of the host-guest complexes formed with either $\mathbf{P M V}^{2+}$ or $\mathbf{D M V}^{2+}$ with CB[7] were carried out with an ion-trap instrument (Bruker Esquire 3000plus, Bruker Daltonic, Bremen, Germany) equipped with an Agilent Technologies 6120 quadrupole equipped with an electrospray (ESI) interface. The sample solutions were continuously introduced into the spectrometer source with a syringe pump (Kd Scientific) with a flow rate of $800 \mu \mathrm{L} . \mathrm{h}^{-1}$. For electrospray ionization, the drying gas was heated at $250{ }^{\circ} \mathrm{C}$ and its flow was set at $6 \mathrm{~L} \cdot \mathrm{min}^{-1}$. The capillary exit voltage was fixed at $5 \mathrm{kV}$ and the skimmer voltage was varied from 50 to $200 \mathrm{~V}$ in order to optimize the signal responses. Scanning was performed from $\mathrm{m} / \mathrm{z}=100$ to 1500 . The stoichiometries of the pseudorotaxanes formed with $\mathbf{C B}$ [7] were investigated by electrospray mass spectrometry (ESI-MS) in the positive mode in aqueous solutions. The ionization of the viologen derivatives and complexes (mainly observed as mono- or doubly positively charged species) takes place by reduction, deprotonation and/or by addition of sodium cations. Fragmentations such as demethylation were also observed. The ESI-MS data were obtained for a $55 \mu \mathrm{M}$ solution of $\mathbf{P M V ^ { 2 + }}$ combined to 5 equivalents of $\mathbf{C B}[7]$ and for $50 \mu \mathrm{M}$ solution of $\mathbf{D P V}^{2+}$ combined to 4 equivalent of $\mathbf{C B}$ [7].

PMV $^{++}$Pimerization in Aqueous Solution. UV-Vis.-NIR absorption spectra (220 nm - $1400 \mathrm{~nm}$ ) of increasing concentration of $\mathbf{P M V}^{\mathbf{}}$ (prepared by addition of sodium dithionite under a controlled atmosphere of argon $)$ in $1 \mathrm{~mL}\left(10^{-4} \mathrm{M} \geq\left[\mathbf{M P V}^{\circ+}\right] \geq 10^{-5} \mathrm{M}\right)$ or $0.5 \mathrm{~mL}\left(2 \times 10^{-3} \mathrm{M} \geq\left[\mathbf{M P V}^{\circ+}\right] \geq 2.5 \times\right.$ $\left.10^{-4} \mathrm{M}\right) 0.1 \mathrm{M}$ phosphate solutions $(\mathrm{pH} 7.0$ ) were recorded in $10 \mathrm{~mm}$ or $2 \mathrm{~mm}$ optical cells, respectively, at $25{ }^{\circ} \mathrm{C}$ (Dual Cell Pelletier Accessory) with a Cary 5000 spectrophotometer. The absorbances at any wavelength have been correlated to the absorptivities of both the monomer and the dimer, which are related by:

$$
A_{\mathrm{t}}=\frac{1}{2}\left[\varepsilon_{\mathrm{d}} C_{\mathrm{t}}+\frac{\left(2 \varepsilon_{\mathrm{m}}-\varepsilon_{\mathrm{d}}\right) \sqrt{\left(1+8 K_{\text {Dim }} C_{\mathrm{t}}\right)-1}}{4 K_{\text {Dim }}}\right]_{1,2}
$$

With $K_{\text {Dim }}=\left[\left(\mathbf{M P V}^{\bullet+}\right)_{2}\right] /\left[\mathbf{M P V}^{\bullet+}\right]^{2}$

The data have been processed with the Origin program and allowed us to evaluate the dimerization constant $\left(\log K_{\text {Dim }}\right.$ value of 3.5(1)) and to calculate the electronic spectra of $\mathbf{M P V}^{\circ+}$ under its monomeric and dimeric states (Error! Reference source not found.B).

Spectrophotometric Titration of $\mathbf{P M V}^{\bullet+}$ by $\mathbf{C B}[7]$. To determine the association constant of the $\mathbf{P M V}^{\bullet+} \subset \mathbf{C B}$ [7] inclusion complex, $1 \mathrm{~mL}$ of $\mathbf{P M V}^{2+}\left(5 \times 10^{-5} \mathrm{M}\right)$ was reacted with an excess of sodium dithionite (sodium hydrosulfite or sodium dithionite, $\mathrm{Na}_{2} \mathrm{~S}_{2} \mathrm{O}_{4}, 85 \%$, Sigma Aldrich) in a $10 \mathrm{~mm}$ 
Hellma quartz optical cell in water at $\mathrm{pH} 7$ (0.1 M phosphate buffer). The solution was constantly flushed with $\mathrm{O}_{2}$ - free argon to avoid re-oxidation of the $\mathbf{P M V}{ }^{\bullet+}$ radicals. The $[\mathbf{C B}[7]]_{0} /\left[\mathbf{P M V} \mathbf{v}^{\bullet+}\right]_{0}$ ratio was varied from 0 to 3.09. Special care was taken to ensure that complete equilibration was attained. After each addition, a UV-Vis.-NIR spectrum was recorded from 220 to $1500 \mathrm{~nm}$ on a Cary 5000 (Agilent) spectrophotometer maintained at $25.0(2){ }^{\circ} \mathrm{C}$ by the flow of a Dual Cell Pelletier Accessory (Cary Varian).

Spectrophotometric and Kinetic Titration of $\mathbf{P M V}^{\bullet+}$ by CB[7]. In the absence of $\mathbf{C B}[7]$ in water, the monoradical cationic $\mathbf{D P V}{ }^{\circ+}$, that was generated with an excess of freshly prepared $\mathrm{O}_{2}$-free $\mathrm{Na}_{2} \mathrm{~S}_{2} \mathrm{O}_{4(\text { aq) }}$, has a strong tendency to rapidly dimerize/oligomerize leading to fast formation of insoluble particles (Figure S2) Exposure of the latter solution to air reinstates the $\mathbf{D P V}^{2+}$ (i.e. $\mathbf{D P V}^{2+}$ is unable to dimerize/oligomerize) and leads to colourless and limpid solution.

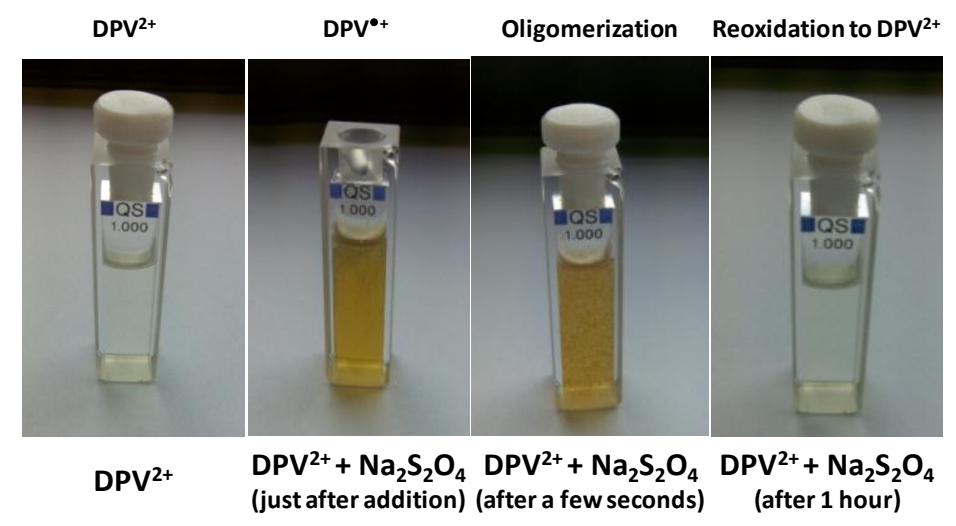

Figure S2. Solutions of $\mathbf{D P V}{ }^{2+}$ before and after addition of $\mathrm{Na}_{2} \mathrm{~S}_{2} \mathrm{O}_{4}$ showing the formation of an insoluble aggregate that re-dissolves upon re-oxidation under open air conditions.

To overcome these limitations, time resolved absorption spectrophotometry was employed (stopped flow apparatus equipped with a diode array spectrophotometer) and allowed measuring the absorption spectrum of $\mathbf{D P V}^{\text {o+ }}$ in the milliseconds time range prior its dimerization and further fast oligomerization. Using such an approach, an absorption spectrophotometric titration of the chemically generated $\mathbf{D P V}^{\circ+}$ by $\mathbf{C B}[7]$ was performed (only the first absorption spectrum of repeated spectral kinetic experiments was recorded for each of the $[\mathbf{C B}[7]] /\left[\mathbf{D P V}^{\circ+}\right]$ ratio considered). By contrast with $\mathbf{D P V}^{2+}$ and $\mathbf{C B}$ [7], the statistical processing of the absorption spectral data set allowed us to evidence the formation of only the [2]pseudorotaxane $\mathbf{D P V}^{*+} \subset \mathbf{C B}$ [7] that is characterized by a stability constant of $\log K_{\mathbf{D P V}+{ }^{+} \mathbf{C B}[7]}=4.9(1)$. It is noteworthy that the stability of the $\mathbf{D P V}^{\circ+} \subset \mathbf{C B}[7]$ species is also comparable to that measured for the homologous [2]pseudorotaxane $\mathbf{P M V}{ }^{{ }^{+}} \subset \mathbf{C B}$ [7] $\left(\log K_{\mathbf{M P V} \cdot+\subset \mathbf{C B}[7]}\right.$ $=4.60(7)$ ) once again confirming similar binding mode for each of the considered radical host-guest complexes. 
Statistical Processing of the Absorption Spectrophometric Data. The spectrophotometric data were processed using the Specfit program ${ }^{3-6}$ which adjusts the stability constants and the corresponding extinction coefficients of the species formed at equilibrium. Specfit uses factor analyses to reduce the absorbance matrix and to extract the eigenvalues prior to the multi-wavelength fit of the reduced data set according to the Marquardt algorithm. ${ }^{7,8}$

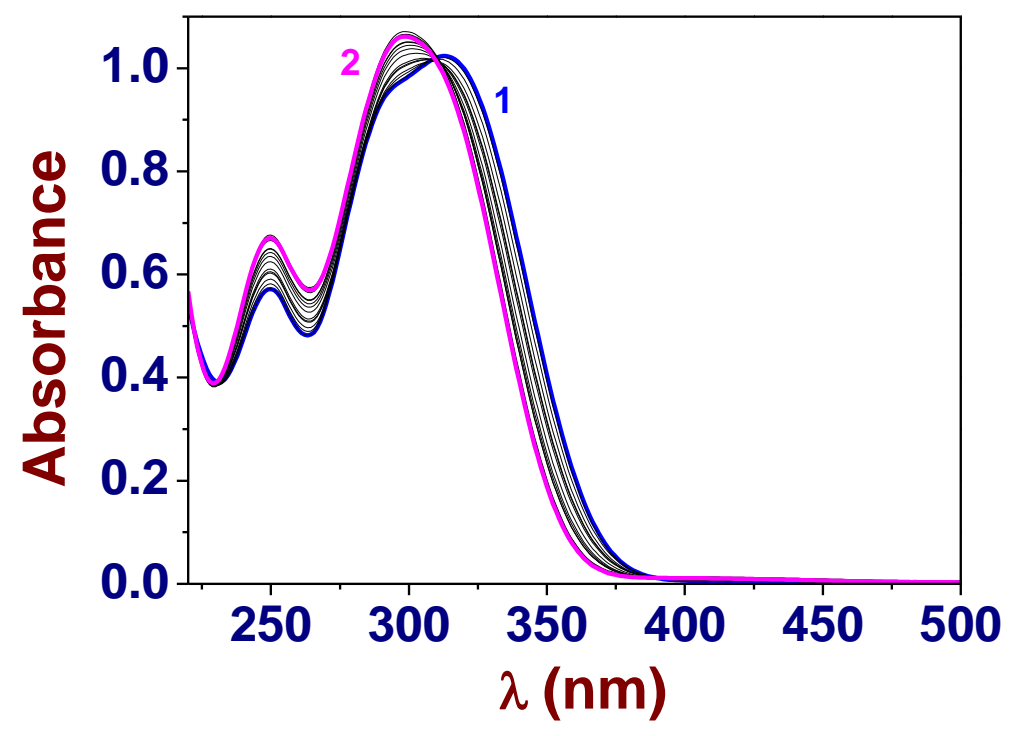

(A)

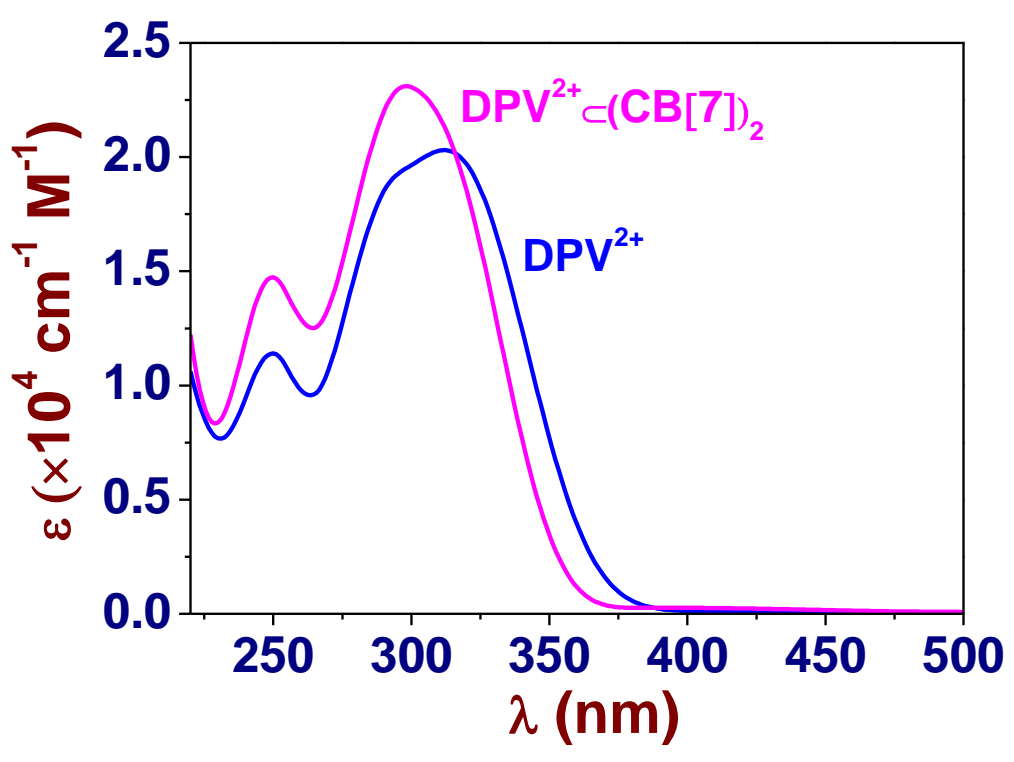

(B)

Figure S3. (A) UV-Vis absorption titration of $\mathrm{DPV}^{2+}$ by $\mathrm{CB}$ [7] in water and (B) electronic absorption spectra of $\mathrm{DPV}^{2+}$ and its inclusion complex with $\mathrm{CB}[7]\left(\mathrm{DPV}^{2+} \subset(\mathrm{CB}[7])_{2}\right)$. Solvent: water buffered at pH 7.0 with $0.1 \mathrm{M} \mathrm{Na}_{2} \mathrm{HPO}_{4} / \mathrm{NaH}_{2} \mathrm{PO}_{4}$. $\left[\mathrm{DPV}^{2+}\right]_{0}=5.0 \times 10^{-5} \mathrm{M}$; (1) $[\mathrm{CB} 7]_{0} /\left[\mathrm{DPV}^{2+}\right]_{0}=0$; (2) $[\mathrm{CB}[7]]_{0} /\left[\mathrm{DPV}^{2+}\right]_{0}=5.50 ; l=1 \mathrm{~cm} ; T=25.0(1){ }^{\circ} \mathrm{C}$. The absorption spectra were corrected for dilution effects. 


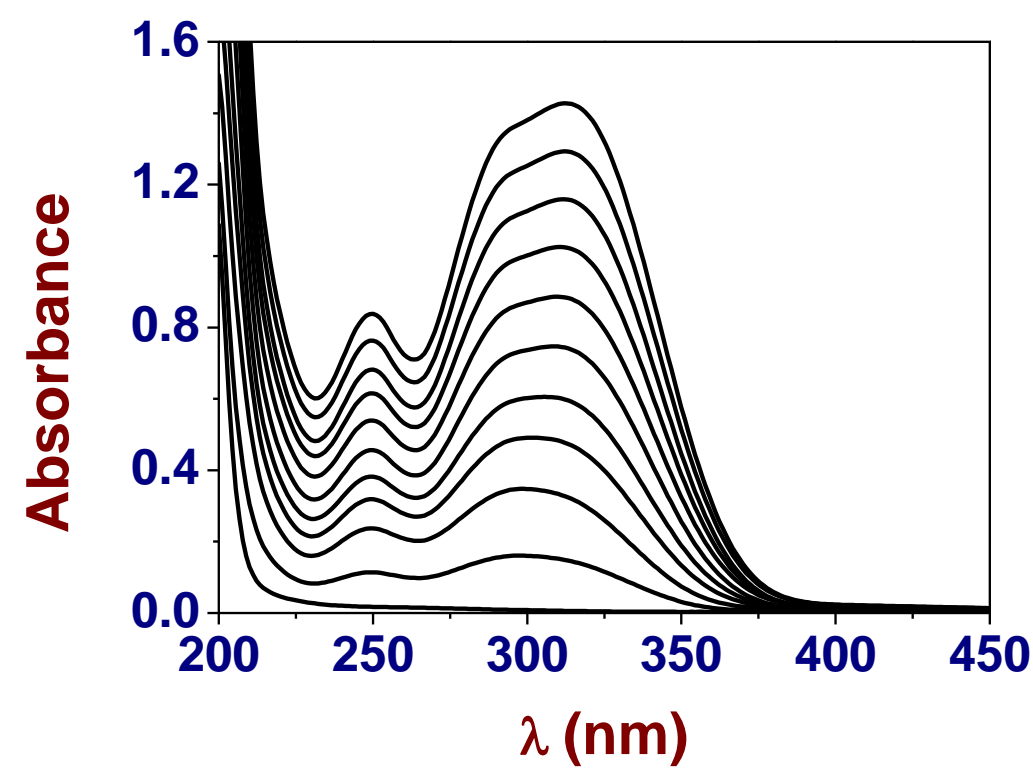

(A)

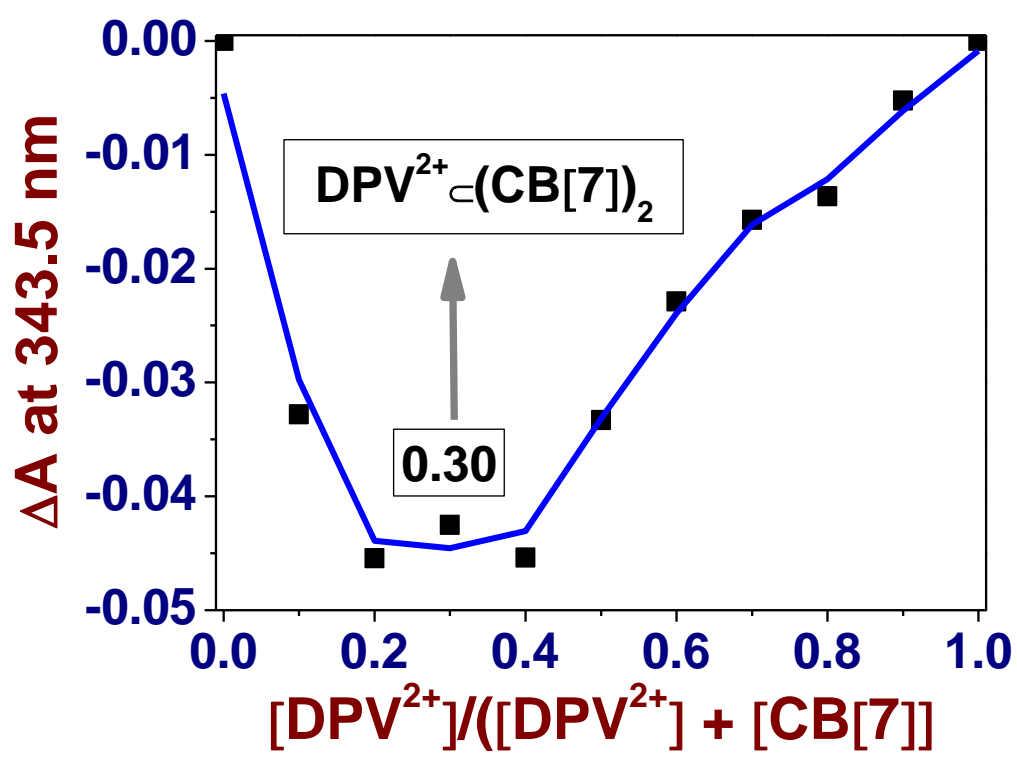

(B)

Figure S4. (A) Absorption spectra recorded and (B) Job plot ( $\triangle \mathrm{A}$ at $343.5 \mathrm{~nm}$ ) calculated after mixing $\mathrm{DPV}^{2+}$ and $\mathrm{CB}[7]$ at $\mathrm{pH}$ 7.5. $\left(\left[\mathrm{DPV}^{2+}\right]_{0}+[\mathrm{CB} 7]_{0}\right)=7.0 \times 10^{-5} \mathrm{M}$; Solvent: water buffered at $\mathrm{pH} 7.0$ with $0.1 \mathrm{M} \mathrm{Na}_{2} \mathrm{HPO}_{4} / \mathrm{NaH}_{2} \mathrm{PO}_{4} ; l=1 \mathrm{~cm} ; T=25.0(1){ }^{\circ} \mathrm{C}$.

Assuming the stability constant calculated for $\mathrm{PMV}^{2+} \subset \mathrm{CB}[7]\left(\log K_{\mathrm{PMV}^{2+} \subset \mathrm{CB}[7]}=6.1(3)\right)$ as being closely related to the first binding event occurring for $\mathrm{DPV}^{2+}$ and $\mathrm{CB}[7]\left(K_{\mathrm{DPV}^{2+} \subset \mathrm{CB}[7]}\right)$, the statistical recognition of a second $\mathrm{CB}[7]$ macrocycle $\left(K_{\mathrm{DPV}^{2+} \subset(\mathrm{CB}[7])_{2}} / K_{\mathrm{DPV}^{2+} \subset \mathrm{CB}[7]}\right)$ would lead to a global stability constant of $\log \beta_{\mathrm{DPV}^{2+} \subset(\mathrm{CB}[7])_{2}}=11.6$ far above the one experimentally determined (i.e. negative cooperativity). This suggests that strong steric interactions between the two $\mathrm{CB}[7]$ macrocycles are 
taking place within the [3]-pseudorotaxane $\mathrm{DPV}^{2+} \subset(\mathrm{CB}[7])_{2}$ and lead to altered recognition properties with respect to $\mathrm{PMV}^{2+} \subset \mathrm{CB}[7]$.

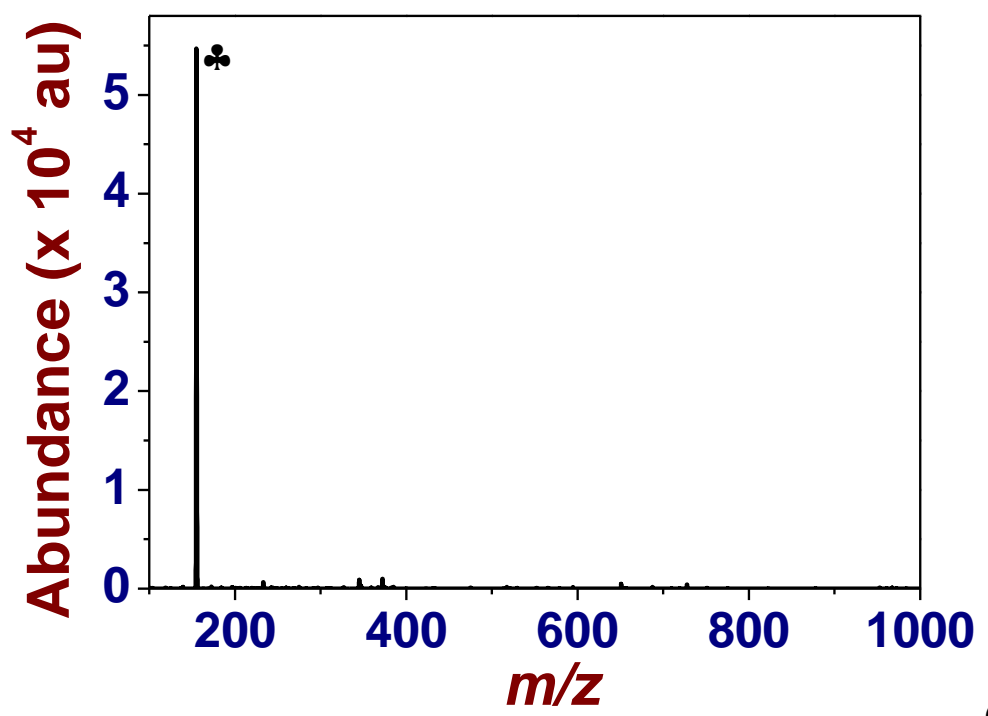

(A)

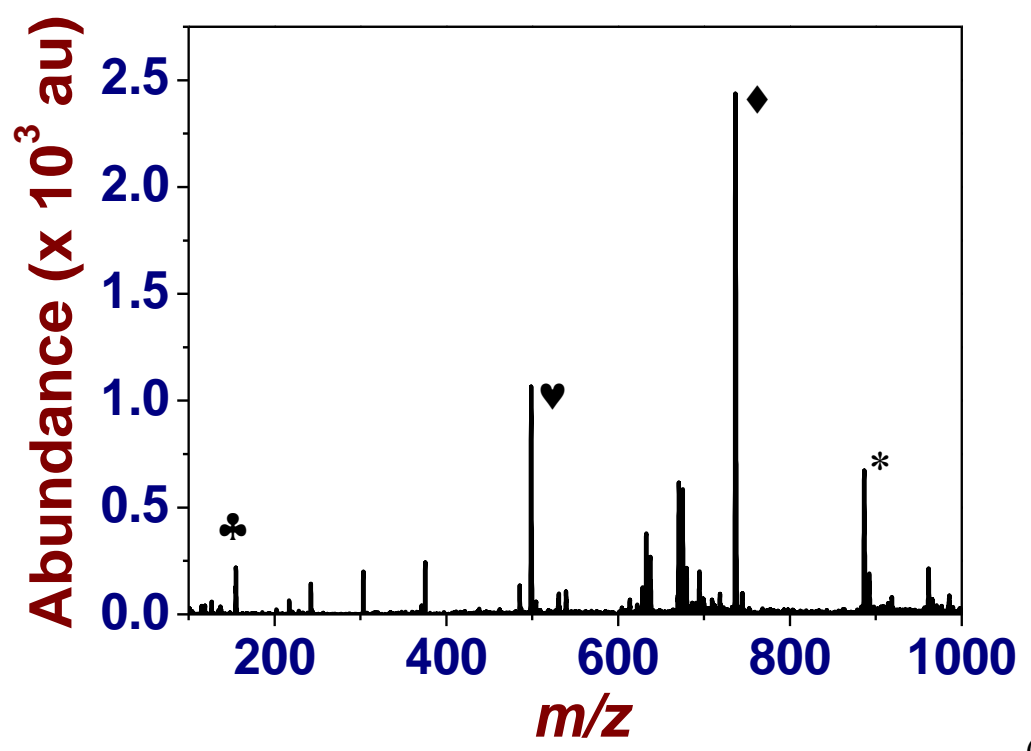

Figure S5. (A) ESI mass spectrum of free $\mathrm{DPV}^{2+}$. $\left[\mathrm{DPV}^{2+}\right]=5 \times 10^{-5} \mathrm{M}$. Solvent: $\mathrm{H}_{2} \mathrm{O}$; positive mode. $\mathrm{Vc}=20 \mathrm{~V} . *=(\mathrm{DPV})^{2+}, \mathrm{m} / z_{\exp }=155.15, \mathrm{~m} / z_{\text {theo }}=155.08$. (B) ESI mass spectrum of inclusion complexes of $\mathrm{DPV}^{2+}$ with $\mathrm{CB}[7]$. [DPV $\left.{ }^{2+}\right]=5 \times 10^{-5} \mathrm{M}$; [CB[7]] $=2 \times 10^{-4} \mathrm{M}$. Solvent: $\mathrm{H}_{2} \mathrm{O}$; positive mode. $\mathrm{Vc}=20 \mathrm{~V} . \boldsymbol{*}=(\mathrm{DPV})^{2+}, \mathrm{m} / z_{\mathrm{exp}}=155.15, \mathrm{~m} / z_{\text {theo }}=155.08 . \vee=(\mathrm{DPV}+\mathrm{Na}+\mathrm{CB}[7])^{2+}, \mathrm{m} / z_{\mathrm{exp}}=$ $498.75, m / z_{\text {theo }}=498.79 . \quad=(\mathrm{DPV}+\mathrm{CB}[7])^{2+}, \mathrm{m} / \mathrm{z}_{\exp }=736.50, \mathrm{~m} / z_{\text {theo }}=736.55 . *=$ $(\mathrm{DPV}+\mathrm{Na}+2 \mathrm{CB}[7])^{3+}, \mathrm{m} / \mathrm{z}_{\exp }=886.50, \mathrm{~m} / \mathrm{z}_{\text {theo }}=886.35$. The ESI-MS spectra were limited to the areas of interest. No peaks were detected in the excluded $\mathrm{m} / \mathrm{z}$ regions. 


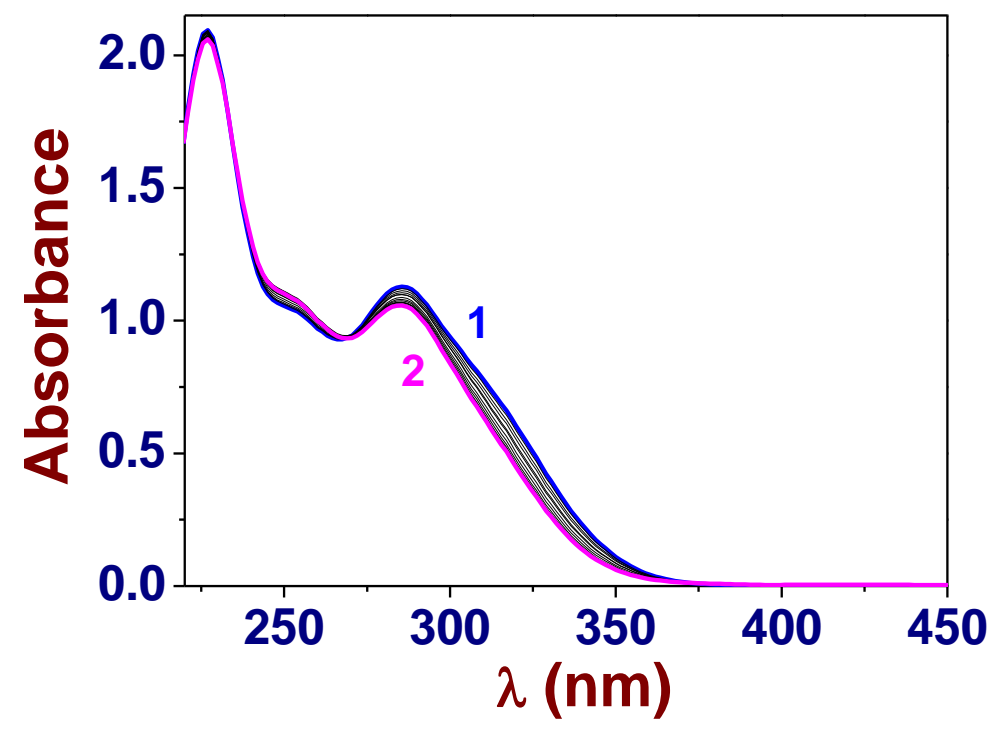

(A)

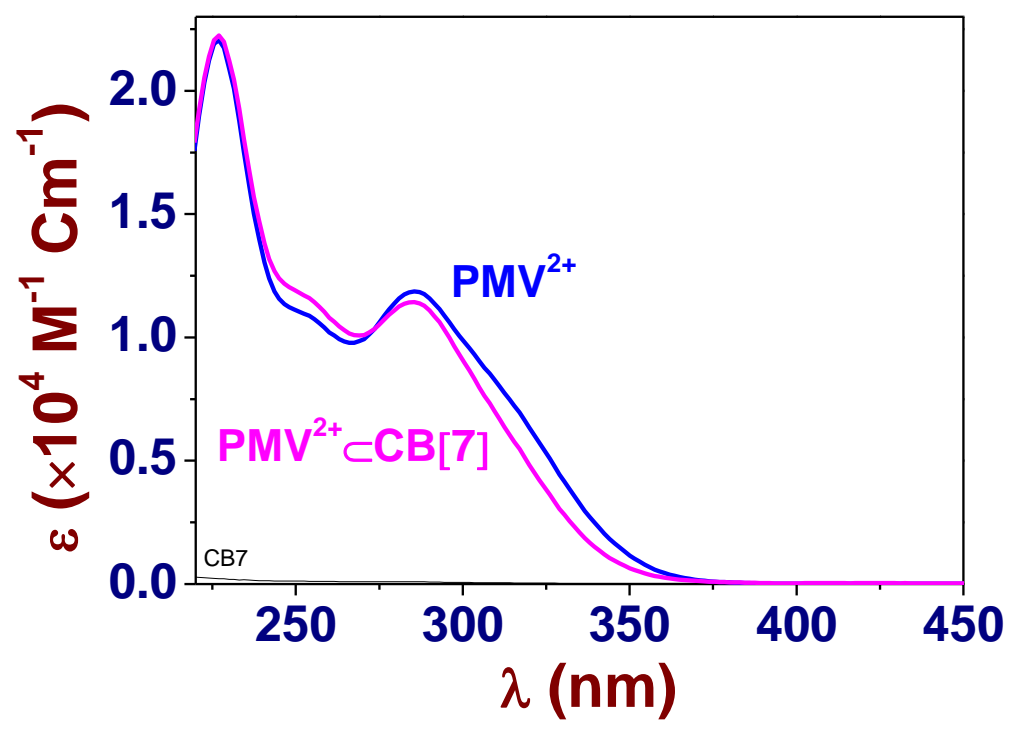

(B)

Figure S6. (A) UV-Vis absorption titration of $\mathrm{PMV}^{2+}$ by $\mathrm{CB}$ [7] in water and (B) electronic absorption spectra of $\mathrm{PMV}^{2+}$ and of its inclusion complex with $\mathrm{CB}[7]$ ( $\left.\mathrm{PMV}^{2+} \subset \mathrm{CB}[7]\right)$. Solvent: water buffered at pH 7.0 with $0.1 \mathrm{M} \mathrm{Na}_{2} \mathrm{HPO}_{4} / \mathrm{NaH}_{2} \mathrm{PO}_{4}$. $\left[\mathrm{PMV}^{2+}\right]_{0}=9.50 \times 10^{-5} \mathrm{M}$; (1) $[\mathrm{CB} 7]_{0} /\left[\mathrm{PMV}^{2+}\right]_{0}=0$; (2) $[\mathrm{CB}[7]]_{0} /\left[\mathrm{PMV}^{2+}\right]_{0}=3.75 ; l=1 \mathrm{~cm} ; T=25.0(1){ }^{\circ} \mathrm{C}$. The absorption spectra are not corrected from dilution effects. 


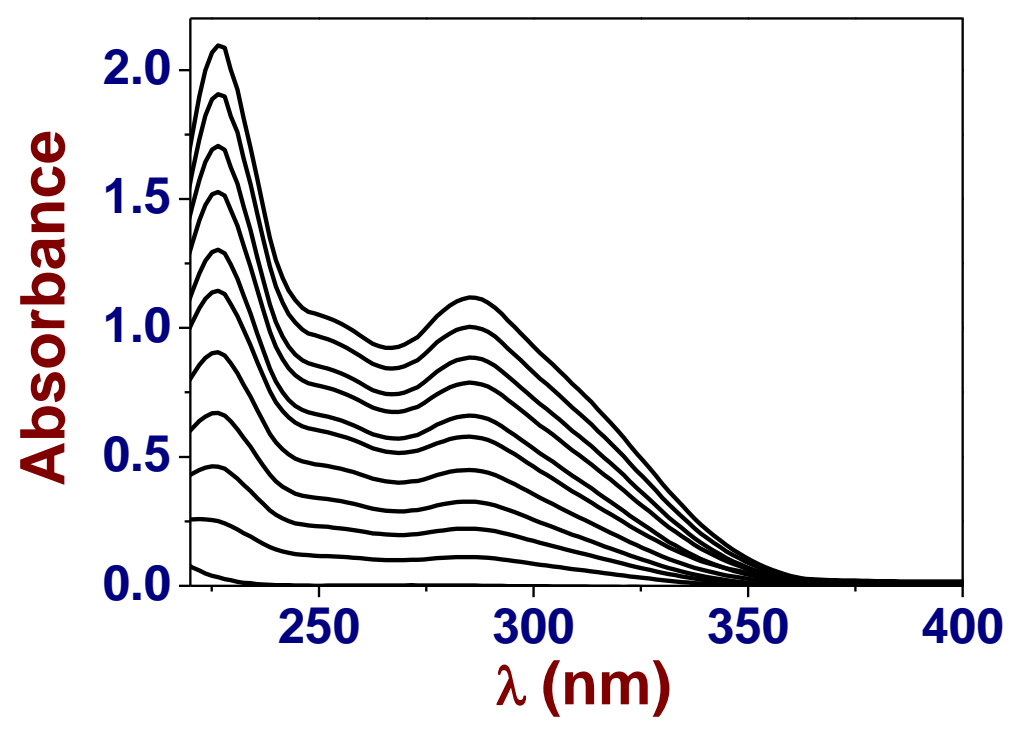

(A)

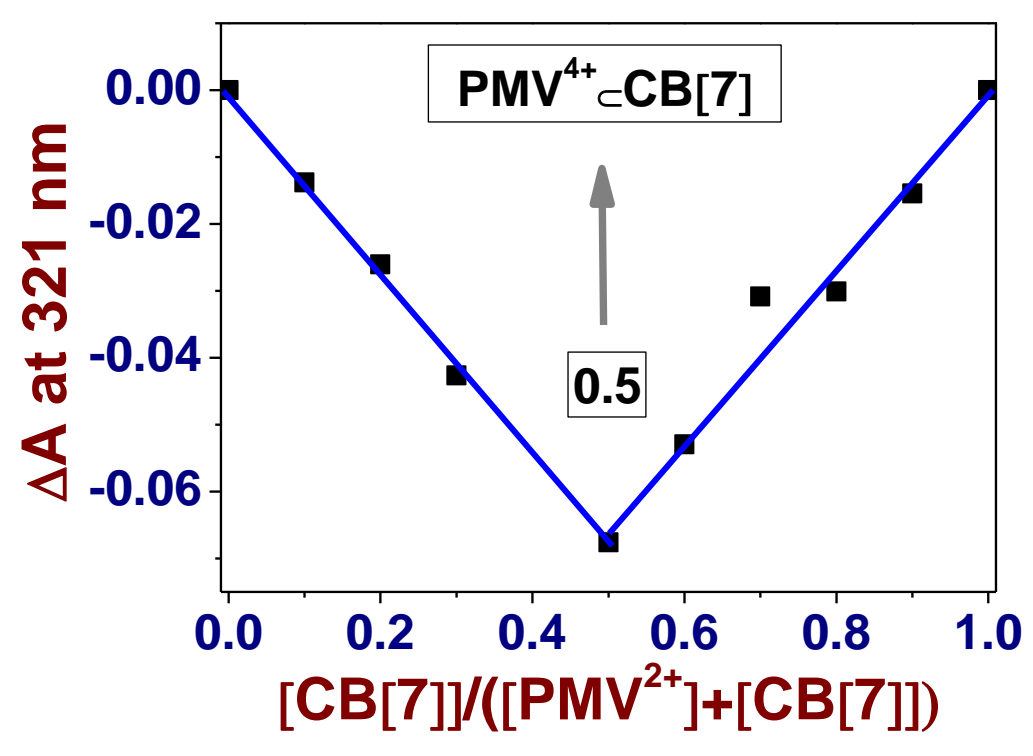

(B)

Figure S7. (A) Absorption spectra recorded and (B) Job plot ( $\Delta \mathrm{A}$ at $321 \mathrm{~nm})$ calculated after mixing $\mathrm{PMV}^{2+}$ and $\mathrm{CB}[7]$ at $\mathrm{pH}$ 7.5. $\left(\left[\mathrm{PMV}^{2+}\right]_{0}+[\mathrm{CB} 7]_{0}\right)=9.50 \times 10^{-5} \mathrm{M}$; Solvent: water buffered at $\mathrm{pH} 7.0$ with $0.1 \mathrm{M} \mathrm{Na}_{2} \mathrm{HPO}_{4} / \mathrm{NaH}_{2} \mathrm{PO}_{4} ; l=1 \mathrm{~cm} ; T=25.0(1){ }^{\circ} \mathrm{C}$. 


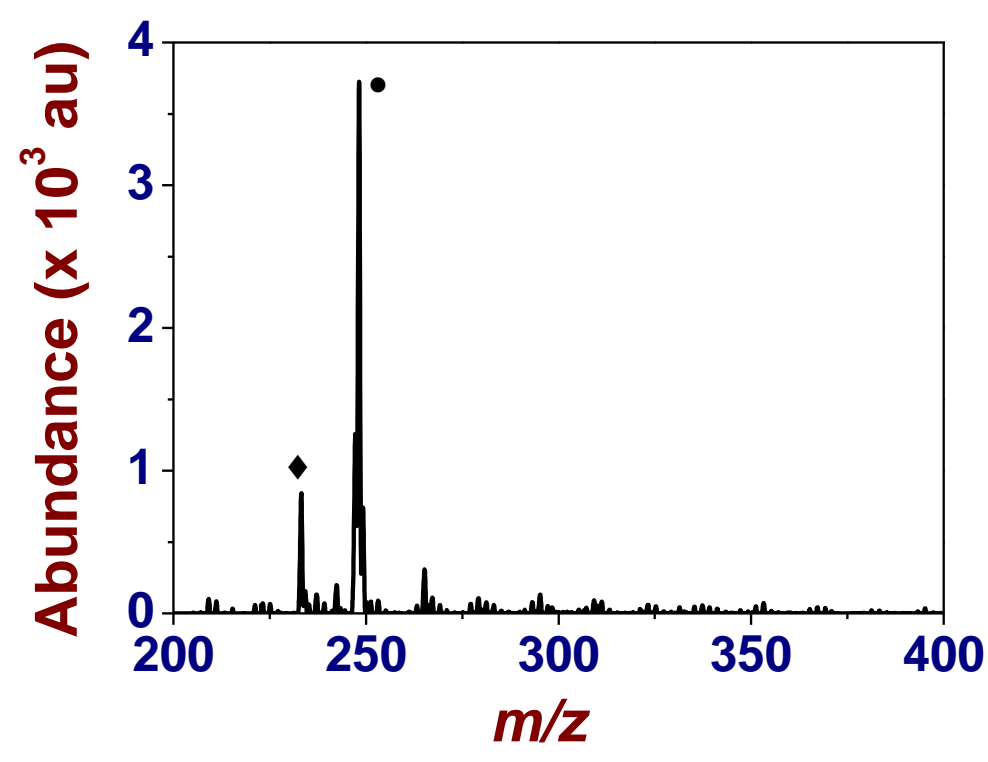

(A)

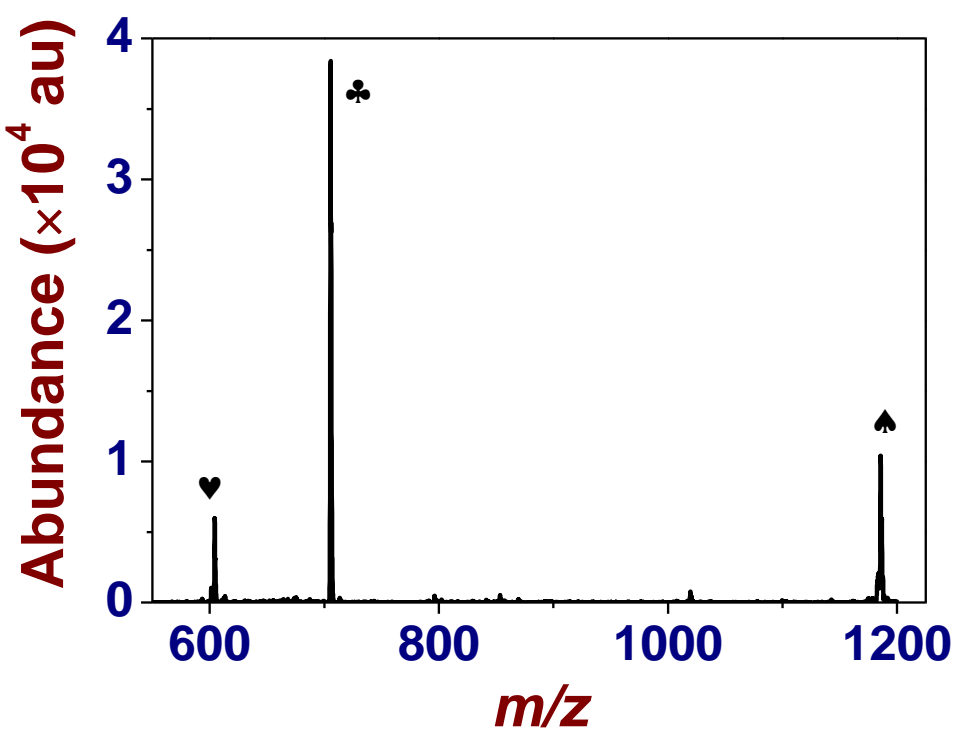

(B)

Figure S8. (A) ESI mass spectrum of free $\mathrm{PMV}^{2+}$. $\left[\mathrm{PMV}^{2+}\right]=5.5 \times 10^{-5} \mathrm{M}$. Solvent: $\mathrm{H}_{2} \mathrm{O}$; positive

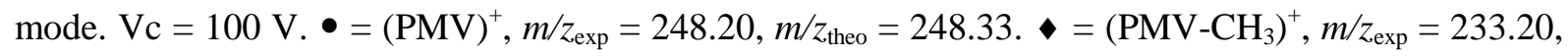
$m / z_{\text {theo }}=233.11$. (B) ESI mass spectrum of inclusion complexes of $\mathrm{PMV}^{2+}$ with $\mathrm{CB}[7] .\left[\mathrm{PMV}^{2+}\right]=5.5$ x $10^{-5} \mathrm{M} ;[\mathrm{CB}[7]]=2.75 \times 10^{-4} \mathrm{M}$. Solvent: $\mathrm{H}_{2} \mathrm{O}$; positive mode. $\mathrm{Vc}=300 \mathrm{~V} . \boldsymbol{\vee}=(\mathrm{CB}[7]+2 \mathrm{Na})^{2+}$, $\mathrm{m} / \mathrm{z}_{\exp }=604.40, \mathrm{~m} / z_{\text {theo }}=604.16 . \quad *=(\mathrm{PMV}+\mathrm{CB}[7])^{2+}, \mathrm{m} / \mathrm{z}_{\exp }=705.55, \mathrm{~m} / z_{\text {theo }}=705.24 . \boldsymbol{\omega}=$ $(\mathrm{CB}[7]+\mathrm{Na})^{+}, m / z_{\exp }=1185.65, \mathrm{~m} / z_{\text {theo }}=1185.33$. The ESI-MS spectra were limited to the areas of interest. No peaks were detected in the excluded $\mathrm{m} / \mathrm{z}$ regions. 
In the absence of $\mathrm{CB}[7]$ in water, however, the monoradical cationic $\mathrm{DPV}^{\bullet+}$, that was generated with an excess of freshly prepared $\mathrm{Na}_{2} \mathrm{~S}_{2} \mathrm{O}_{4(\mathrm{aq})}$, has a strong tendency to dimerize/oligomerize leading to the formation of insoluble aggregates. Exposure of the latter solution to air regenerates the $\mathrm{DPV}^{2+}($ i.e. $\mathrm{DPV}^{2+}$ is unable to dimerize/oligomerize) and leads to a colorless and limpid solution. To overcome this limitation, time-resolved absorption spectrophotometry was employed. We measured the absorption spectrum of $\mathrm{DPV}^{\circ+}$ in the millisecond time range (Fig. S7) prior to its dimerization and further fast oligomerization (i.e. dimerization constant for $\mathrm{MV}^{\circ+}, \log K_{\mathrm{Dim}}=2.70$ and for $\mathrm{PMV}^{\circ+}, \log$ $K_{\text {Dim }}=3.5(1)$, see Fig. S8).

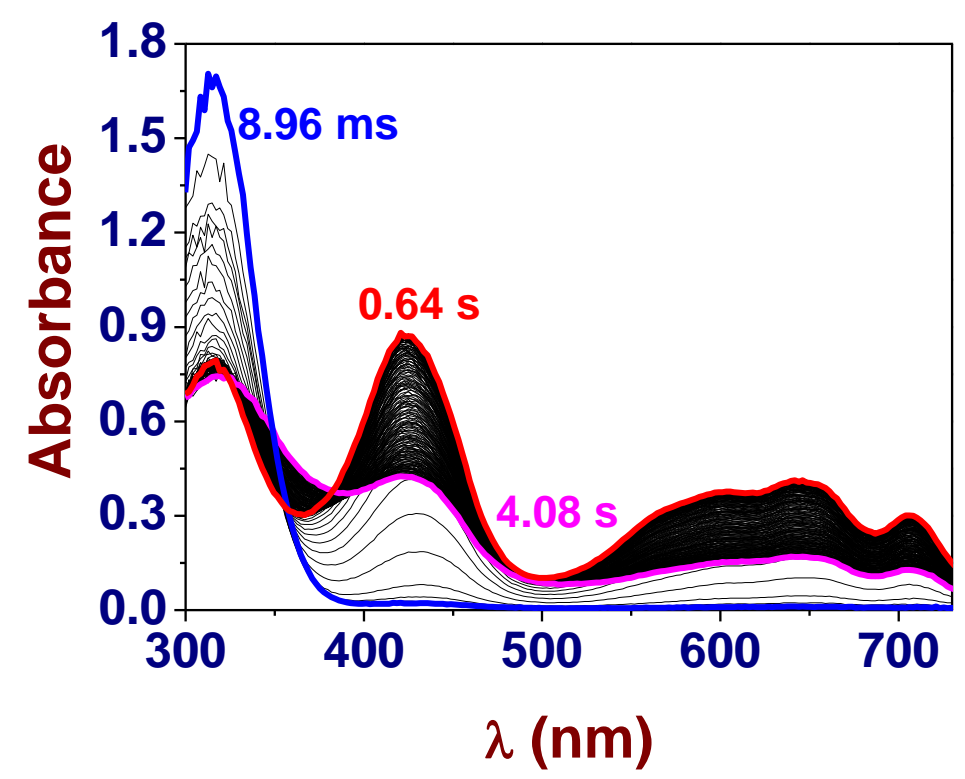

(A)

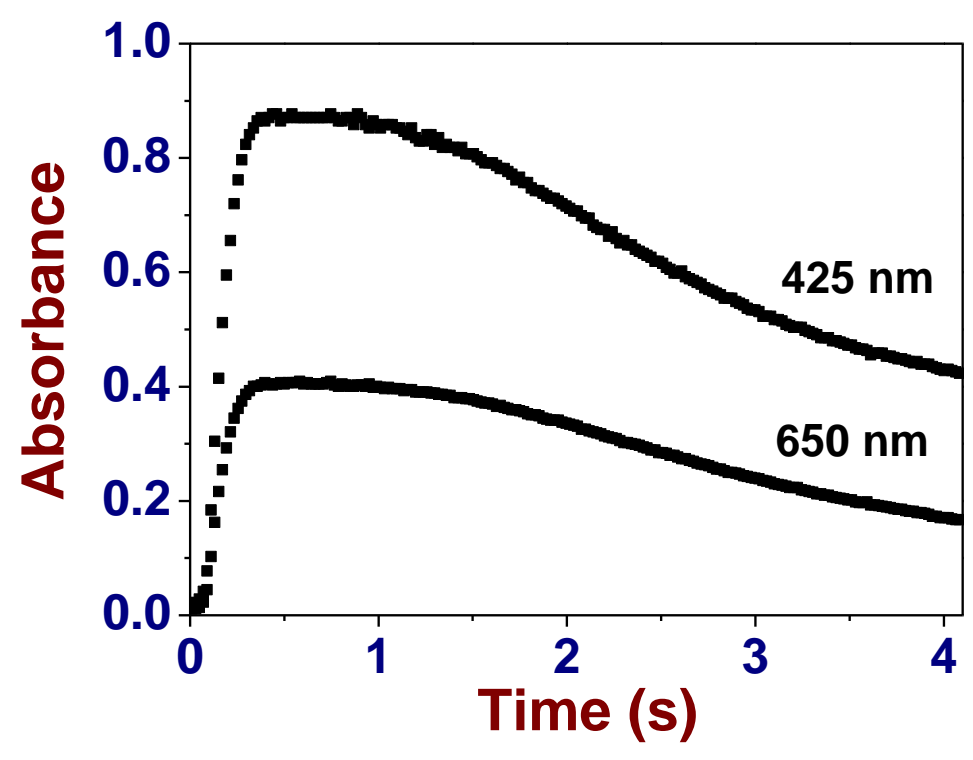

Figure S9. (A) Time-resolved absorption spectra of $\mathrm{DPV}^{2+}$ in the presence of sodium dithionite $\left(\mathrm{Na}_{2} \mathrm{~S}_{2} \mathrm{O}_{4}\right)$ showing the very fast formation $\left(<1\right.$ second) of the 1 electron reduced form $\mathrm{DPV}^{\bullet+}$ and the 
fast oligomerization and (B) absorption variation at $425 \mathrm{~nm}$ and $650 \mathrm{~nm}$ (absorptions that are characteristic of the $\mathrm{DPV}^{\circ+}$ species). Solvent: water buffered at $\mathrm{pH} 7.0$ with $0.1 \mathrm{M} \mathrm{Na}_{2} \mathrm{HPO}_{4}$ / $\mathrm{NaH}_{2} \mathrm{PO}_{4} ; l=1 \mathrm{~cm} ; T=25.0(1){ }^{\circ} \mathrm{C} .\left[\mathrm{DPV}^{2+}\right]=5.23 \times 10^{-5} \mathrm{M} ;\left[\mathrm{Na}_{2} \mathrm{~S}_{2} \mathrm{O}_{4}\right]=9.88 \times 10^{-4} \mathrm{M}$.

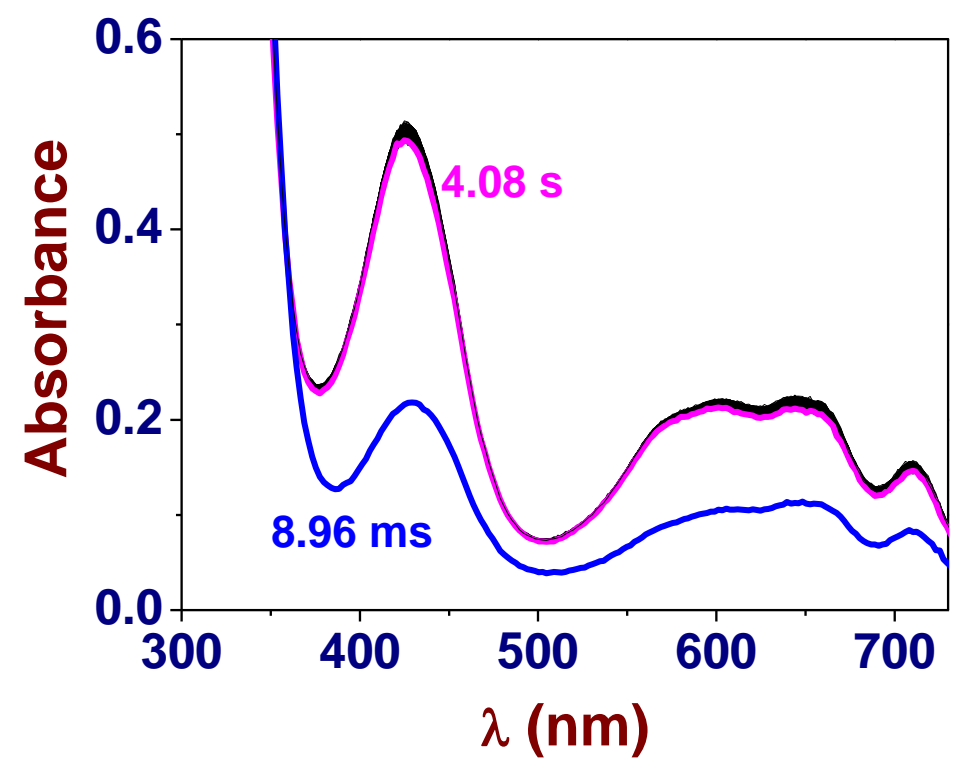

(A)

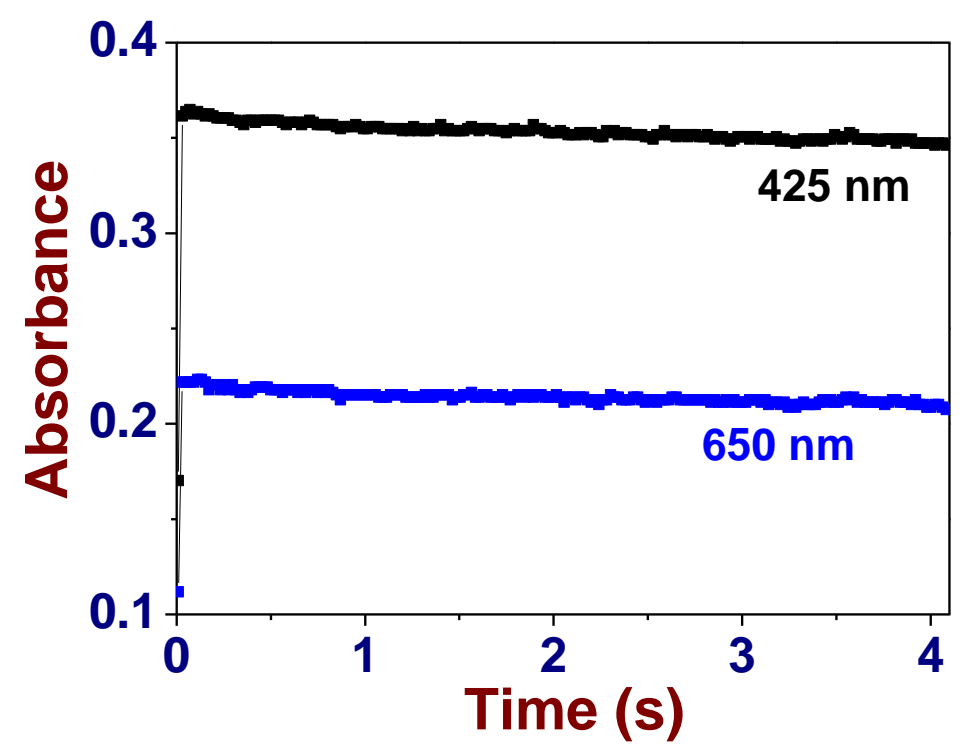

(B)

Figure S10. (A) Time-resolved absorption spectra of $\mathrm{DPV}^{2+}$ in the presence of 1.51 equivalent of $\mathrm{CB}[7]$ and sodium dithionite showing the very fast formation $(<50 \mathrm{~ms})$ of the 1 electron reduced form $\mathrm{DPV}^{\bullet+}$ and of the $\mathrm{DPV}^{\bullet+} \subset \mathrm{CB}[7]$ complex which prevent further oligomerization and (B) absorption variation at $425 \mathrm{~nm}$ and $650 \mathrm{~nm}$ (absorptions that are characteristic of the DPV ${ }^{\circ+}$ species). Solvent: water buffered at pH 7.0 with $0.1 \mathrm{M} \mathrm{Na}_{2} \mathrm{HPO}_{4} / \mathrm{NaH}_{2} \mathrm{PO}_{4} ; l=1 \mathrm{~cm} ; T=25.0(1){ }^{\circ} \mathrm{C}$. $\left[\mathrm{DPV}^{2+}\right]=5.23 \times$ $10^{-5} \mathrm{M} ;\left[\mathrm{Na}_{2} \mathrm{~S}_{2} \mathrm{O}_{4}\right]=9.88 \times 10^{-4} \mathrm{M}$. 


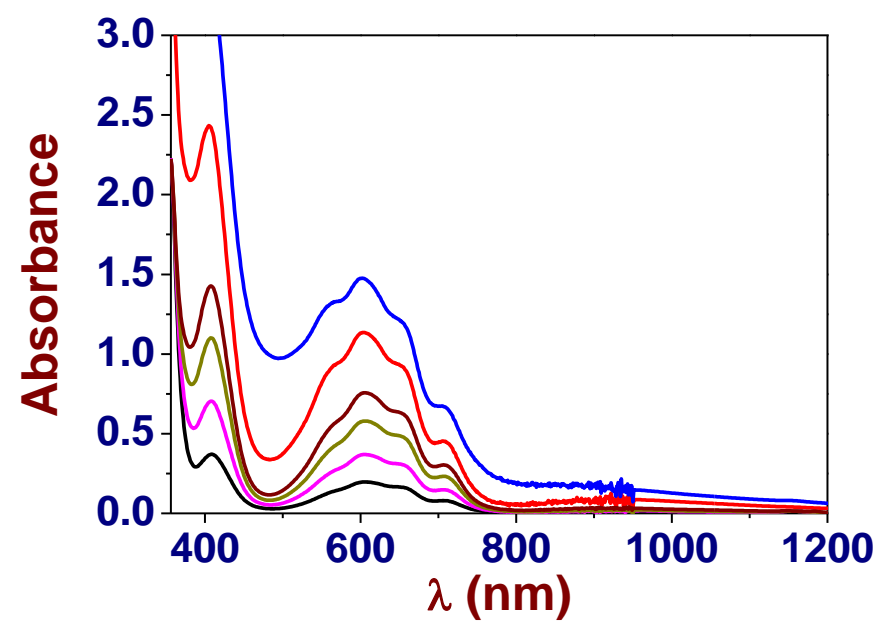

(A)

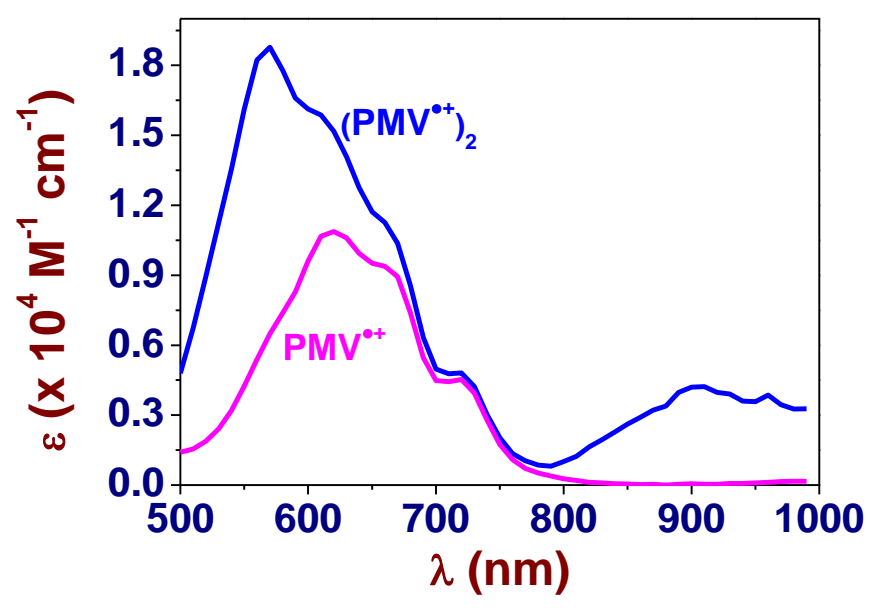

(B)

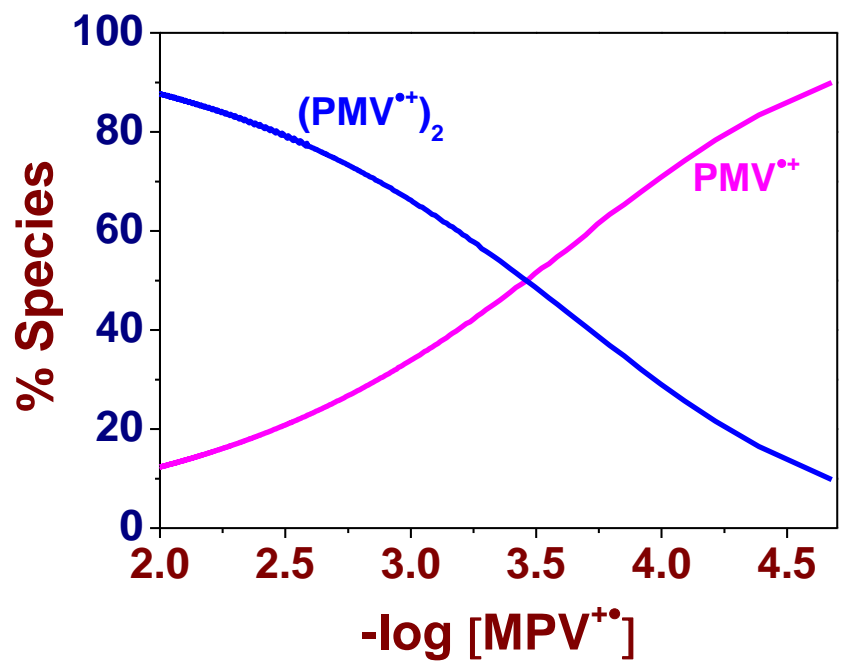

Figure S11. (A) Dimerization absorption titration of $\mathrm{PMV}^{\circ+}$ in aqueous solution, (B) electronic UVVis-NIR absorption spectra of $\mathrm{PMV}^{\cdot+}$ compared to its dimer $\left(\mathrm{PMV}^{*+}\right)_{2}$ and $(\mathrm{C})$ distribution diagram of the monomer versus dimer as a function of $\mathrm{PMV}^{\circ+}$ concentration. Solvent: Water buffered at $\mathrm{pH} 7.0$ with $0.1 \mathrm{M} \mathrm{Na}_{2} \mathrm{HPO}_{4} / \mathrm{NaH}_{2} \mathrm{PO}_{4} .2 .1 \times 10^{-5} \mathrm{M} \leq\left[\mathrm{PMV}^{\circ+}\right]_{0}<5 \times 10^{-4} \mathrm{M} ; T=25.0(1){ }^{\circ} \mathrm{C}$. 


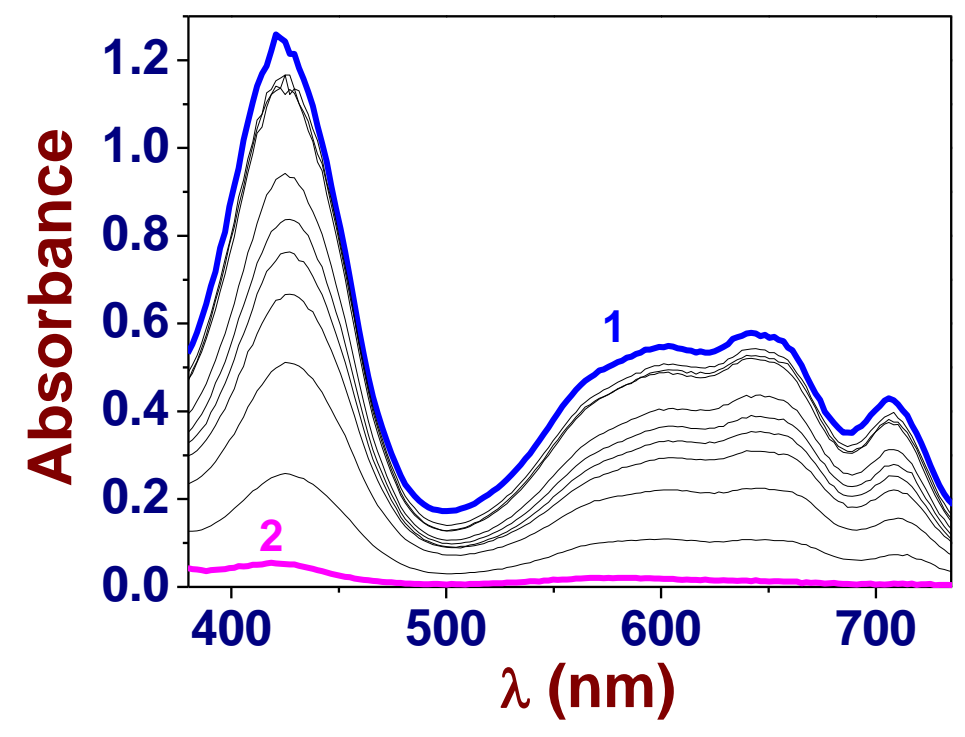

(A)

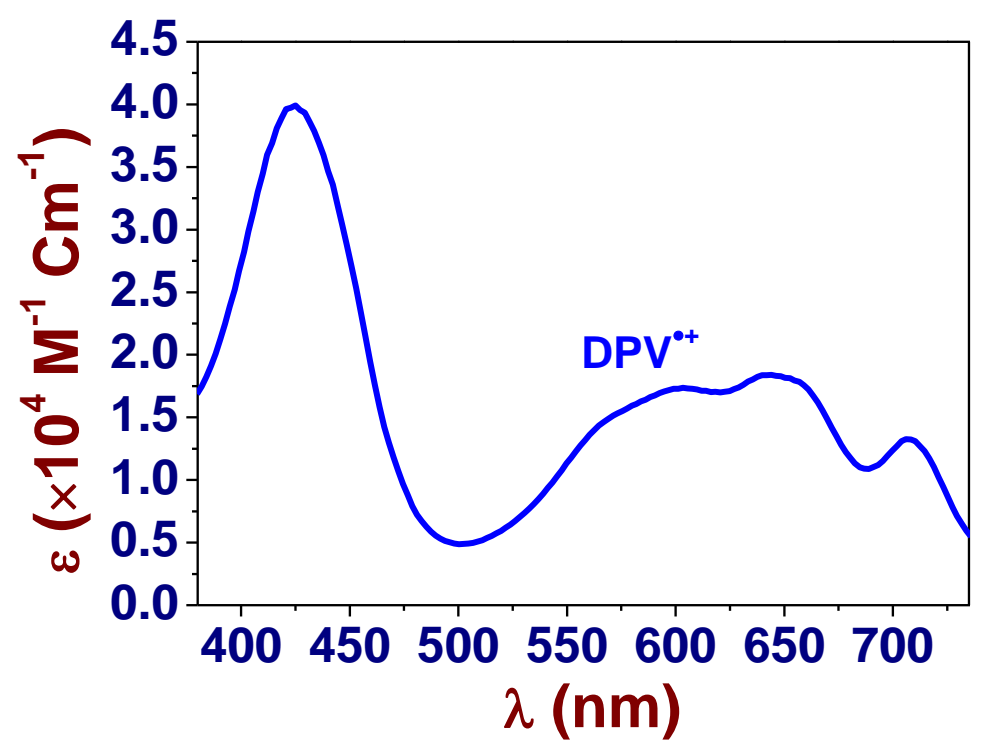

Figure S12. (A) UV-Vis absorption titration of $\mathrm{DPV}^{\text {++ }}$ by $\mathrm{CB}[7]$ in water. (B) Electronic spectra of $\mathrm{PMV}^{*+}$. The inclusion of $\mathrm{DPV}^{*+}$ within the $\mathrm{CB}[7]$ cavity led to an almost complete fading of the $\mathrm{DPV}^{\bullet+}$ absorption in the Vis-NIR region. The electronic absorption spectrum of $\mathrm{DPV}^{\bullet+} \subset \mathrm{CB}[7]$ could not be calculated accurately and was assumed to be as a non colored species during the statistical process. Solvent: water buffered at pH 7.0 with $0.1 \mathrm{M} \mathrm{Na}_{2} \mathrm{HPO}_{4} / \mathrm{NaH}_{2} \mathrm{PO}_{4}$. $\left[\mathrm{DPV}^{\circ+}\right]_{0}=5.23 \times 10^{-5} \mathrm{M}$; (1) $[\mathrm{CB} 7]_{0} /\left[\mathrm{DPV}^{\circ+}\right]_{0}=0 ;(2)[\mathrm{CB}[7]]_{0} /\left[\mathrm{DPV}^{*+}\right]_{0}=2.95 ; l=1 \mathrm{~cm} ; T=25.0(1){ }^{\circ} \mathrm{C}$. The absorption spectra are corrected from dilution effects. 


\begin{tabular}{|c|c|c|c|}
\hline Viologen V & $K_{\mathrm{V} 2+\subset \mathrm{CB}[7]}$ & $\log K_{\text {Dim }}$ & $\log K_{\mathrm{V} \cdot+C \mathrm{CB}[7]}$ \\
\hline $\mathbf{M V}^{2+}$ & $2.0(1) \times 10^{5} \mathrm{M}^{-1}$ & $3.1 \times 10^{2}-8 \times 10^{2} \mathrm{M}^{-19}$ & $6.16 \times 10^{4} \mathrm{M}^{-19}$ \\
\hline $\mathbf{P M V}^{2+}$ & $1.3(9) \times 10^{6} \mathrm{M}^{-1}$ & $3.2(7) \times 10^{3} \mathrm{M}^{-1}$ & $4.0(6) \times 10^{4} \mathrm{M}^{-1}$ \\
\hline $\mathrm{DPV}^{2+}$ & $\begin{array}{l}\beta_{\mathrm{DPV} 2+\subset(\mathrm{CB}[7]) 2}= \\
2.0(4) \times 10^{8} \mathrm{M}^{-2}\end{array}$ & nd & $7.9(1.8) \times 10^{4} \mathrm{M}^{-1}$ \\
\hline
\end{tabular}

Table S1. Thermodynamic parameters of the dimers and [n]pseudorotaxanes formed with viologens and $\mathbf{C B}[7]$.

\section{Dynamic Light Scattering (DLS), FTIR and XPS Characterizations}

Sulfonated particles (300 $\mu \mathrm{L}$, PSS) were mixed with $\mathrm{CB}[7]\left(8 \times 10^{-3} \mathrm{M}\right)$ in $\mathrm{F} 1080.1 \%$ at $\mathrm{pH}=4$, at room temperature overnight. Residual $\mathrm{CB}$ [7] was removed by repeated washings with water and centrifugation, the particles were then re-suspended in deionized water.

\subsection{Dynamic Light Scattering (DLS)}

\begin{tabular}{|c|c|c|c|}
\hline$\zeta$-potential $(\mathbf{m V})$ & $\mathbf{p H}=\mathbf{4}$ & $\begin{array}{c}\mathbf{C B}[\mathbf{7}] \text { (excess) at } \\
\mathbf{p H}=\mathbf{4}\end{array}$ & $\begin{array}{c}\text { After cleaning at } \mathbf{p H} \\
\mathbf{=}\end{array}$ \\
\hline PMs & 0 & -18 & -3 \\
\hline SPMs & 0 & -40 & -45 \\
\hline
\end{tabular}

Table S2: $\zeta$-potential values of polystyrene spheres (PMs) and sulfonated polystyrene spheres (SPMs) before, during and after addition of $\mathrm{CB}[7]$. 
2.2. Fourier Transform Infrared Spectroscopy (FTIR)

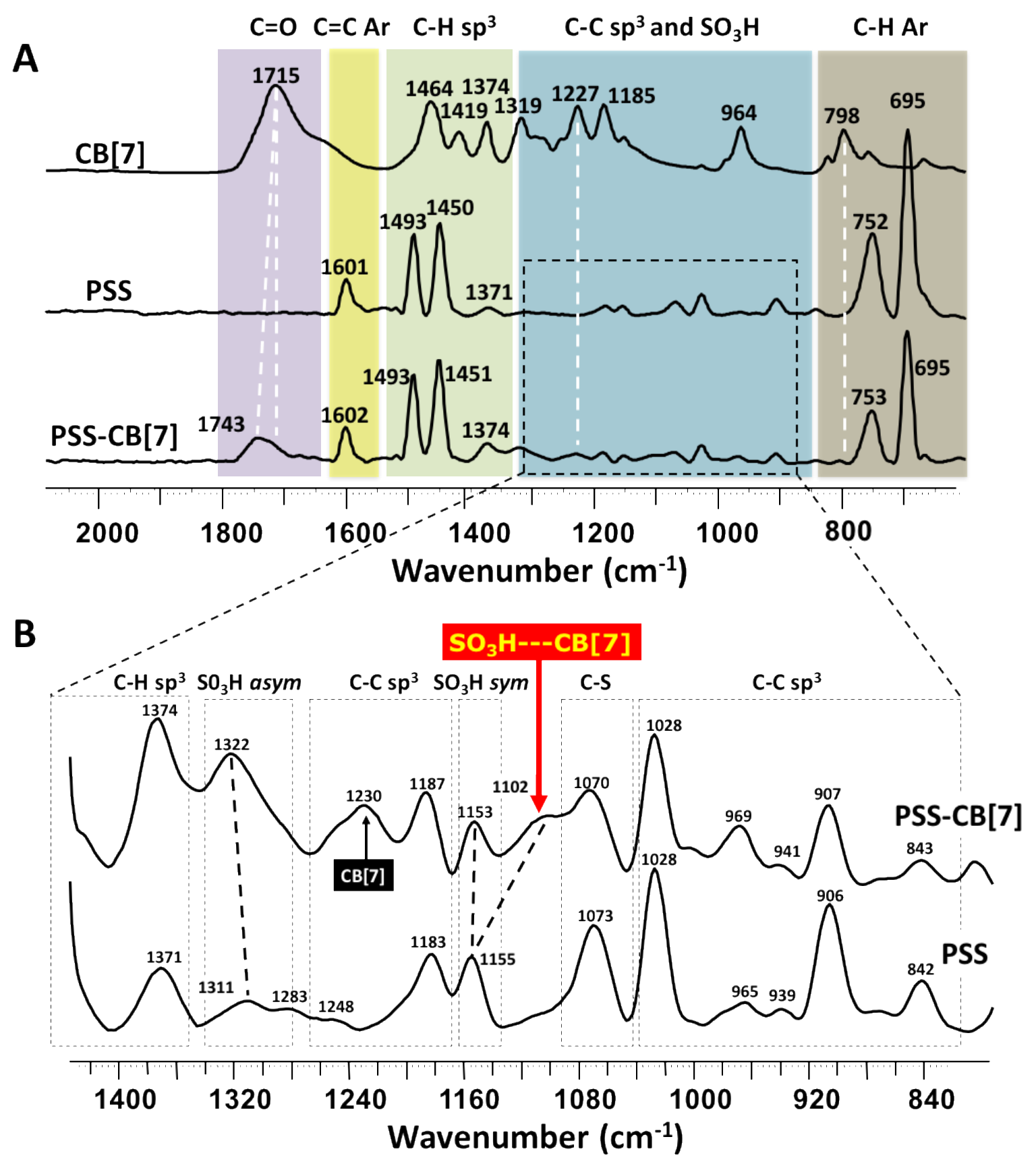

Figure S13. FTIR spectra of A) CB[7], PSS and PSS modified with CB[7], B) PSS and PSS modified with CB[7]

\subsection{X-ray photoelectron spectroscopy (XPS)}

The chemical composition and bonding information about three different types of solids (CB[7], sulfonated particle, CB[7]-modified particle) were analyzed by Kratos Axis Ultra delay-line detector 
(DLD) X-ray photoelectron spectroscopy (XPS) using monochromatic $\mathrm{Mg} \mathrm{K} \alpha$ radiation $(1253.6 \mathrm{eV})$ from the $\mathrm{Mg}$ anode source. High resolution of elemental XPS spectra (C 1s, O 1s, S 2p, N 1s) were collected with $10 \mathrm{eV}$ of pass energy under emission of $10 \mathrm{~mA}$ and anode $\mathrm{HT}$ of $15 \mathrm{kV}$, and 5 sweeps and 0.05 of energy steps were applied to increase the signal-to-noise of the XPS spectra. All obtained high resolution XPS spectra were calibrated by $284.6 \mathrm{eV}$ of $\mathrm{C}$ 1s peak binding energy. In order to investigate the chemical bonding information, the obtained XPS spectra were deconvoluted using XPSPEAK 41 program where a Shirley background and Chi-square test were used.

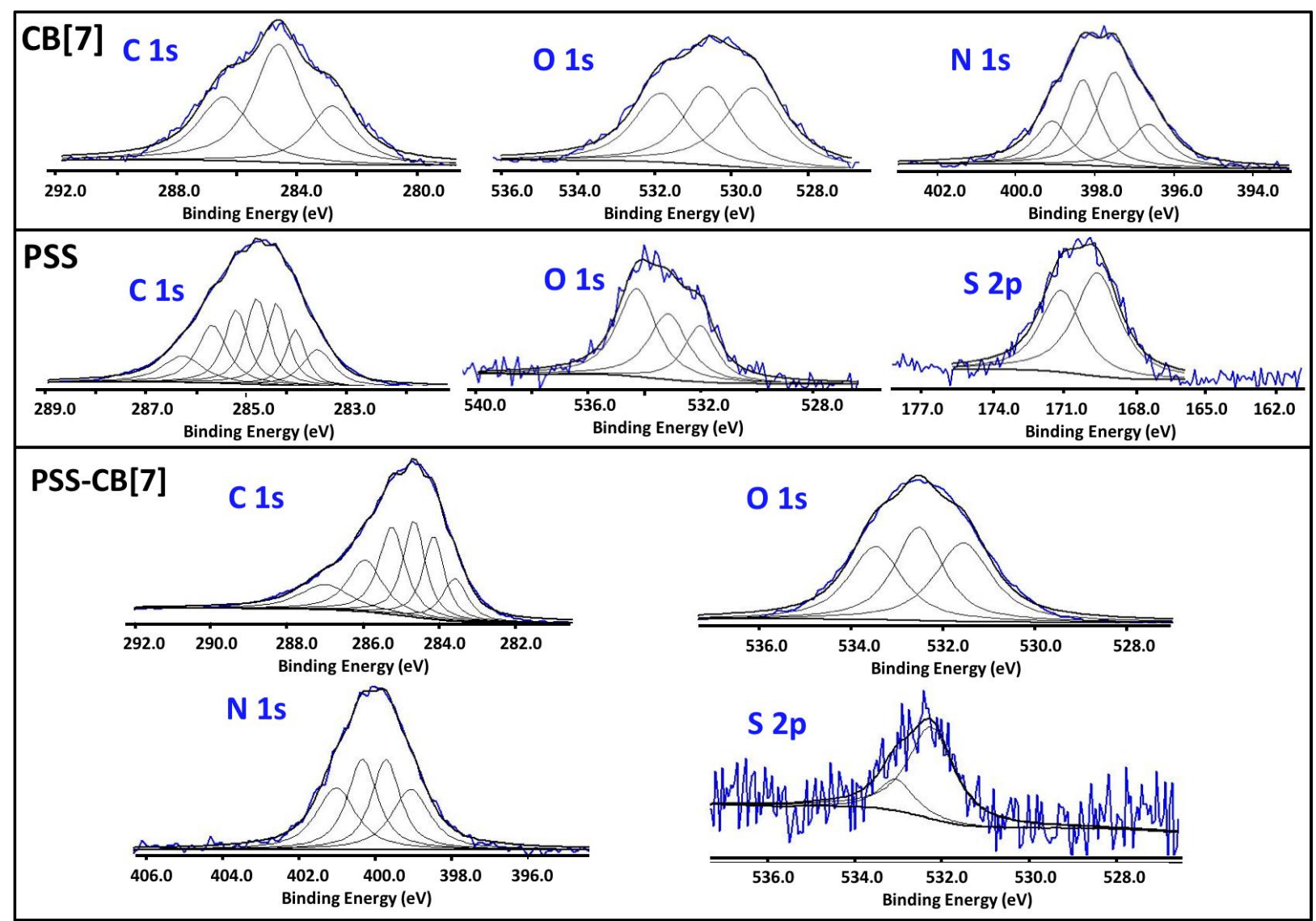

Figure S14. XPS spectra of A) CB[7], sulfonated particles (PSS) and PSS modified with CB[7].

\section{Sulfonated Patchy Particle Synthesis}

Sulfonated patchy particles were fabricated following, with some modifications, the "clusterencapsulation" method previously reported. The sulfonate-modified polystyrene micro-spheres (620 $\mathrm{nm}$ in diameter, $3 \%$ divinylbenzene cross-linked) were synthesized via a surfactant-free emulsion polymerization.

\section{CB[7]-Modified Patchy Particles.}

$\mathrm{CB}$ [7]CPs were prepared at $\mathrm{pH}=4$ by mixing $300 \mu \mathrm{L}$ of sulfated patchy particle suspension $(\sim 0.1 \%$ w/w) with $\mathrm{CB}$ [7] $\left(8 \times 10^{-3} \mathrm{M}\right)$ as a $0.1 \%$ Pluronic F108 solution. 2-patch particle $\mathrm{CB}$ [7]CPs were 
prepared by mixing $100 \mu \mathrm{L}$ of sulfonated patchy particle suspension (2-patch particle, $\sim 0.01 \% \mathrm{w} / \mathrm{w}$ ) with $\mathrm{CB}[7]\left(8 \times 10^{-4} \mathrm{M}\right)$ as a $0.1 \%$ F108 solution. The mixture was then agitated overnight at room temperature. The particles were purified by repeated centrifugation and redispersion in aqueous $0.1 \%$ Pluronic F108, resulting in CB[7]-patch functionalized particles. Prior to cleaning, the patchy particles are randomly aggregated and no specificity or directionality is detected. After a thorough water wash, the patchy particles were found to be stable and no aggregation is observed (see video S1).

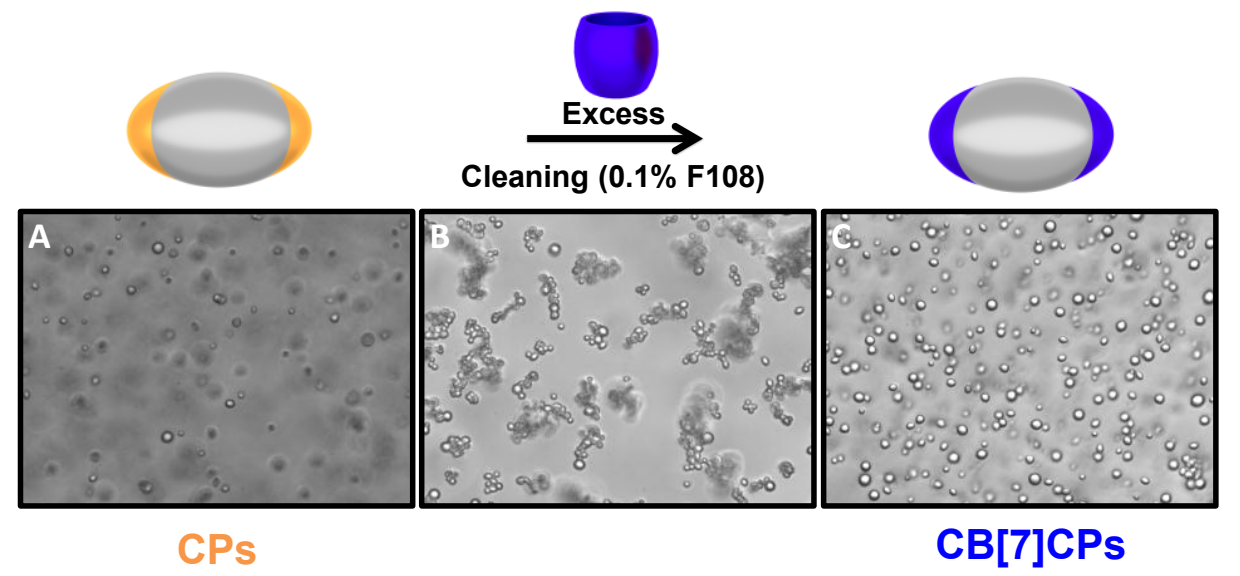

Figure S15. Bright field optical images of A) sulfonated patchy particle, and CB[7]CPs B) before and C) after cleaning the excess of $\mathrm{CB}[7]$. Scale bar, $10 \mu \mathrm{m}$.

\section{DPV-Templated Self-Assembly.}

$\operatorname{DPV}^{2+}\left(0.5 \mu \mathrm{L}, 10^{-2} \mathrm{M}\right)$ and CB[7]CPs (2-patch particle, dimer, $\left.0.01 \% \mathrm{w} / \mathrm{w}, 100 \mu \mathrm{L}\right)$, were mixed together in a micro-centrifuge tube at room temperature and at $\mathrm{pH}=4$. The mixture was agitated for about one hour before $5 \mu \mathrm{L}$ of the particle suspension was transferred to a flat capillary and sealed for microscopic observation (see video 2 and 3).

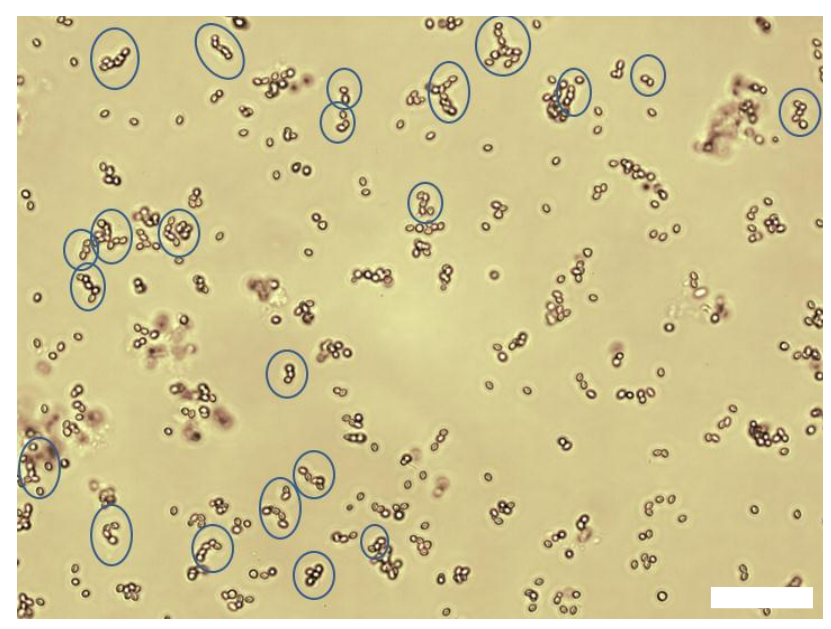

Figure S16. Bright field optical images of CB[7]CPs two-patch particles upon DPV ${ }^{2+}$ addition. Scale bar, $20 \mu \mathrm{m}$. 


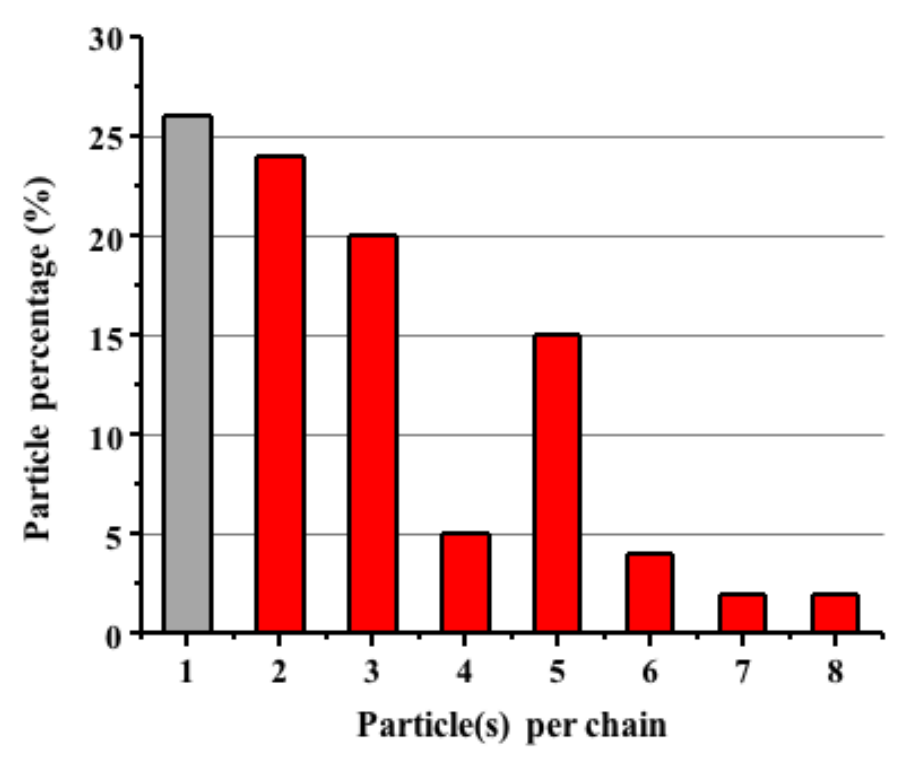

Figure S17. Number distribution of chain assemblies consisting of different number of two-patch particles. The gray bar represents the percentage of free particles in the suspension. Red bars represent the percentages of chain structures containing 2-8 particles. 298 dimers had been considered to draw the distribution.

As a control experiment, methyl viologen $\left(0.5 \mu \mathrm{L}, 10^{-2} \mathrm{M}\right)$ and $\mathrm{CB}[7] \mathrm{CPs}$ (2-patch particle, dimer, $0.01 \% \mathrm{w} / \mathrm{w}, 100 \mu \mathrm{L}$ ), were mixed together in a micro-centrifuge tube at room temperature and at $\mathrm{pH}=$ 4. The mixture was agitated for about one hour before $5 \mu \mathrm{L}$ of the particle suspension was transferred to a flat capillary and sealed for microscopic observation. The CPs were stable and no self-assembly was observed.

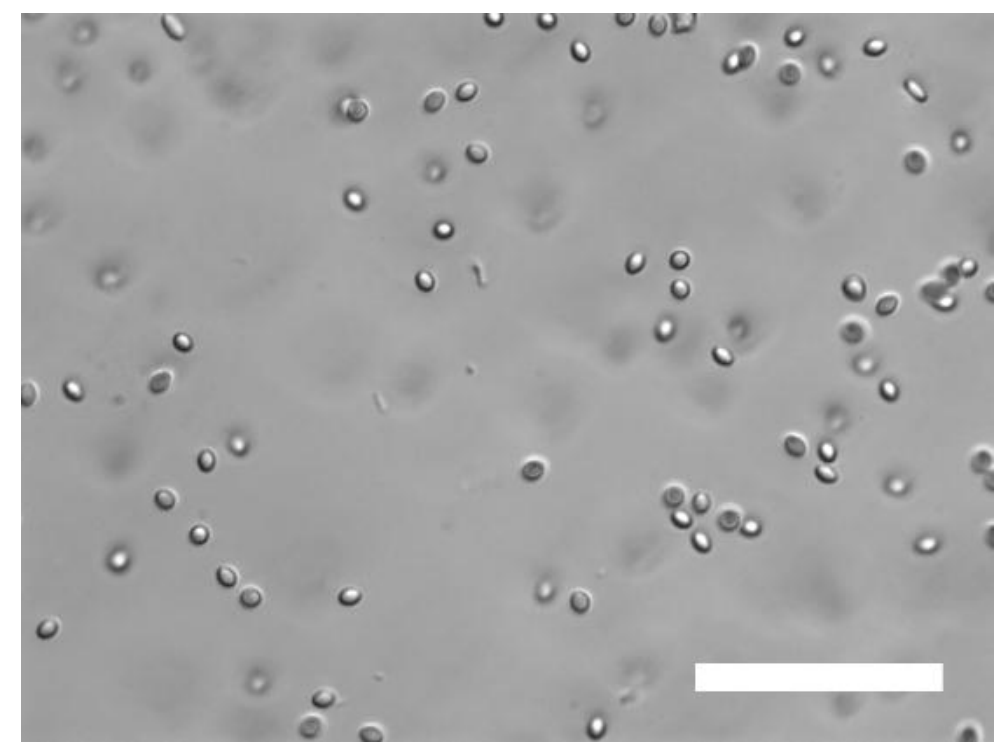

Figure S18. Brightfield optical images of $\mathrm{CB}[7] \mathrm{CPs}$ two-patch particles upon methyl viologen addition. Scale bar, $20 \mu \mathrm{m}$. 


\section{Time-resolved fluorescence measurements}

The fluorescence lifetimes data were analyzed by the iterative reconvolution method using the instrument's software which utilizes the Marquardt-Levenberg algorithm to minimize $\chi^{2}$. A typical instrument function of $c a .30 \mathrm{ps}(\mathrm{fwhm})$ was confirmed after numerical reconvolution. A $0.5-\mathrm{mm}$ demountable cuvette was used to measure to the fluorescence lifetimes of each solid sample, maintaining a front-face excitation geometry, see Table $\mathbf{S} 2$.

The fluorescence decay was analyzed in terms of the multiexponential model

in which the contribution of each time constant to the steady-state intensity is given by

$$
f_{i}=\frac{\alpha_{i} \tau_{i}}{\sum_{j} \alpha_{j} \tau_{j}}
$$

where the sum in the denominator is over all the decay times and amplitudes.

The mean decay time (average lifetime) is then given by

$$
\bar{\tau}=\sum_{i} f_{i} \tau_{i}
$$

, while the amplitude-weighted lifetime is given by

$$
\langle\tau\rangle=\sum_{i} \alpha_{i} \tau_{i}
$$

$\chi^{2}$ values for triple exponential fit.

Essentially, the observed emission is fully dominated by the fluorescence from the fluorophore in question.

\begin{tabular}{|c|c|c|c|c|c|c|}
\hline & DPV $^{2+}$ & $(\mathrm{CB}[7])_{2} \supset \mathrm{DPV}^{2+}$ & $\begin{array}{c}\text { Sulfonated } \\
\text { patchy } \\
\text { particles }\end{array}$ & $\begin{array}{c}\text { Patchy- } \\
\mathrm{CB}[7]\end{array}$ & $\begin{array}{c}\mathrm{DPV}^{2+} \subset \text { Patchy- } \\
\mathrm{CB}[7]\end{array}$ & $\begin{array}{c}\mathrm{DPV}^{2+} \subset \text { Patchy- } \\
\mathrm{CB}[7]+\mathrm{NaCl}\end{array}$ \\
\hline $\begin{array}{c}<\tau> \\
(\mathrm{ns})\end{array}$ & 2.61 & 1.29 & 4.12 & 3.90 & 0.93 & 3.58 \\
\hline $\bar{\tau}(\mathrm{ns})$ & 5.14 & 3.77 & 7.62 & 8.76 & 1.28 & 6.93 \\
\hline
\end{tabular}

Table S3. Steady and multi-exponential fluorescence decay data in solid state $\left(\lambda_{e x}=375 \mathrm{~nm} ; \lambda_{o b s}=\lambda_{e m}\right)$

$\bar{\tau}=\sum_{i} f_{i} \tau_{i} f_{i}=\frac{\alpha_{i} \tau_{i}}{\sum_{j} \alpha_{j} \tau_{j}}$ 
$\langle\tau\rangle=\sum_{i} \alpha_{i} \tau_{i}$

$\chi^{2}$ values for mutli-exponential fit.

The solid state time-resolved fluorescence experiments provided further evidence for the DPV ${ }^{2+}$ ligand's direction of patchy particle-CB[7] self-assembly. Lifetime traces for all samples were found to fit well to functions that had four exponential terms (except the emission decay for $\mathrm{DPV}^{2+} \subset \mathrm{CB}[7] \mathrm{CPs}$ was fitted to three exponential functions), most likely because $\mathrm{DPV}^{2+}$ adopts different conformations. Analysis of the multi-exponential decay patterns (Table S2) indicates that both the amplitude-weighted fluorescence lifetime $\langle\boldsymbol{\tau}\rangle$ and the average fluorescence lifetime $\overline{\boldsymbol{\tau}}$ associated with $\mathrm{DPV}^{2+}$ (2.61 and $5.14 \mathrm{~ns}$, respectively) are shortened in the presence of either CB[7] (1.29 and $3.77 \mathrm{~ns}$, respectively) or the CB[7]CPs (0.93 and $1.28 \mathrm{~ns}$, respectively). However, the CPs and the CB[7]CPs alone have very weak and longer amplitude-weighted lifetimes (4.12 and $3.90 \mathrm{~ns}$, respectively) and average lifetimes (7.62 and $8.76 \mathrm{~ns}$, respectively) when compared with those associated with $\mathrm{DPV}^{2+}$.

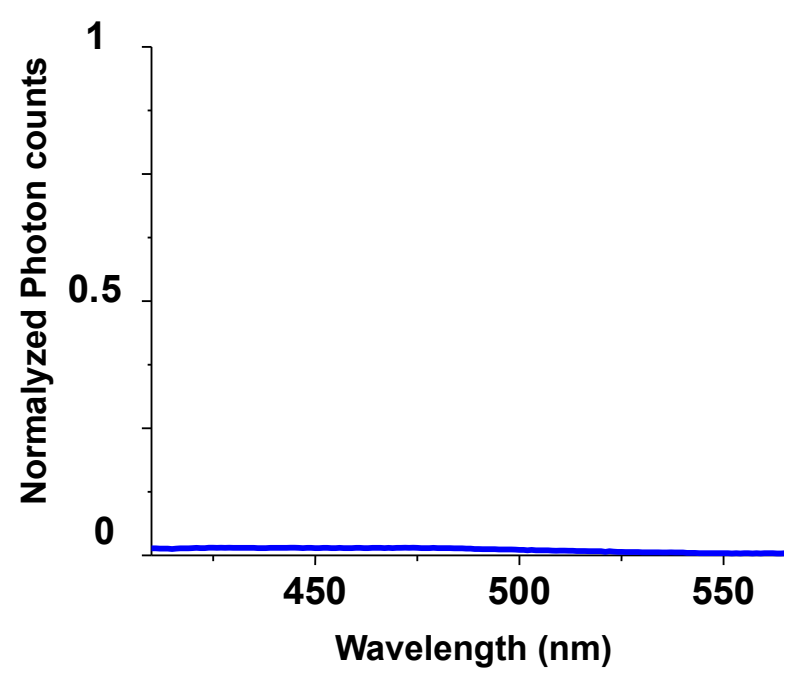

Figure S19. Solid-state fluorescence spectrum of $\mathrm{DPV}^{2+} \subset \mathrm{CB}[7] \mathrm{CPs}$ (blue) after addition of $\mathrm{NaCl}$. $\mathrm{NaCl}$ addition also restores the surface of the patchy particles to their initial state due to removal of the viologen guest which is indicated by no significant emission signal. Fluorescence intensity has been normalized. Measurements in the solid state were performed at $298 \mathrm{~K}$ and $\lambda_{\mathrm{ex}}=375 \mathrm{~nm}$.

Supplementary Video 1: CB[7]CPs two-patch particles suspended in $0.1 \%$ F108. The particles stay stable and no aggregation was observed.

Supplementary Videos 2 and 3: CB[7]CPs two-patch particles upon DPV2+ addition, chain structures formed. The particles were sealed in a flat capillary tube (100 $\mu \mathrm{m}$ in height) for observation. 


\section{References}

\section{Georges, J. Spectrochim. Acta A: Mol. Biomol. Spectro. 1995, 51, 985-994.}

Blank, O.; Davioud-Charvet, E.; Elhabiri, M. Antioxid. Redox Signal. 2012, 17, 544-554.

Gampp, H.; Maeder, M.; Meyer, C. J.; Zuberbühler, A. D. Talanta, 1985, 32, 95-101.

Rossotti, F. J. C.; Rossotti, H. S.; Whewell, R. J. J. Inorg. Nucl. Chem. 1971, 33, 2051-2065.

Gampp, H.; Maeder, M.; Meyer, C. J.; Zuberbühler, A. D. Talanta 1985, 32, 257-264.

Gampp, H.; Maeder, M.; Meyer, C. J.; Zuberbühler, A. D. Talanta 1986, 33, 943-951.

Marquardt, D. W. J. Soc. Ind. Appl. Math. 1963, 11, 431-441.

Maeder, M.; Zuberbuehler, A. D. Anal. Chem. 1990, 62, 2220-2224.

a) Lee, C.; Moon, M. S.; Park, J. W. J. Electroanal. Chem. 1996, 407, 161-167. b) Stargardt, J. F.; Hawkridge, F. M. Anal. Chim. Acta 1983, 146, 1-8. 